Portland State University

PDXScholar

\title{
Overlooked Destinations: Suburban Nodes, Centers, and Trips to Strips
}

Nico Larco

University of Oregon

Robert Parker

University of Oregon

Follow this and additional works at: https://pdxscholar.library.pdx.edu/trec_reports

Part of the Transportation Commons, Urban Studies Commons, and the Urban Studies and Planning Commons

Let us know how access to this document benefits you.

\section{Recommended Citation}

Larco, Nico, Robert Parker. Overlooked Destinations: Suburban Nodes, Centers, and Trips to Strips. OTREC-RR-12-12. Portland, OR: Transportation Research and Education Center (TREC), 2013. https://doi.org/10.15760/trec.43

This Report is brought to you for free and open access. It has been accepted for inclusion in TREC Final Reports by an authorized administrator of PDXScholar. Please contact us if we can make this document more accessible: pdxscholar@pdx.edu. 


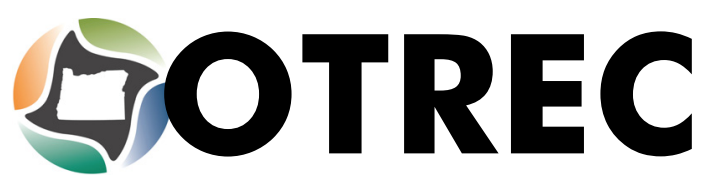

FINAL REPORT

\section{Overlooked Destinations: Suburban Nodes, Centers and Trips to Strips}

OTREC-RR-12-12

August 2013 



\section{OVERLOOKED DESTINATIONS: SUBURBAN NODES, CENTERS AND TRIPS TO STRIPS}

\section{Final Report}

OTREC-RR-12-12

by

Nico Larco, AIA

University of Oregon

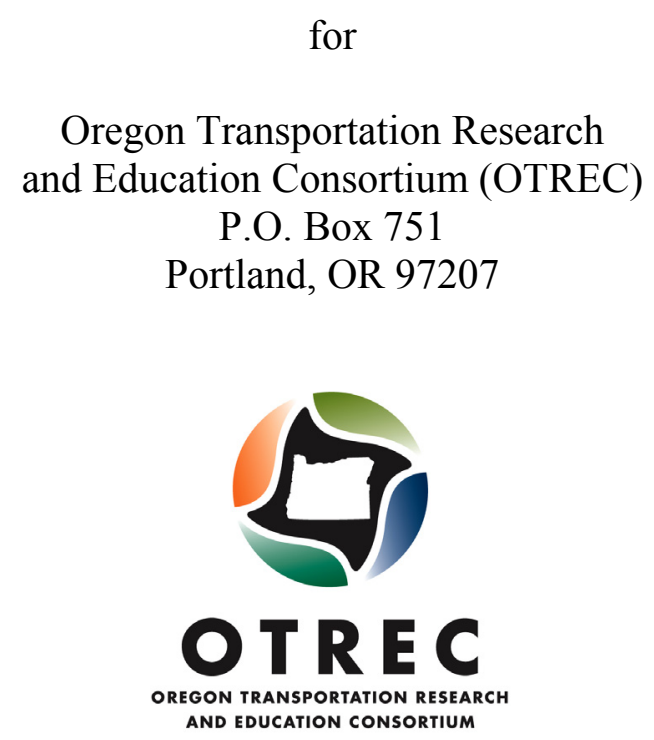

August 2013 



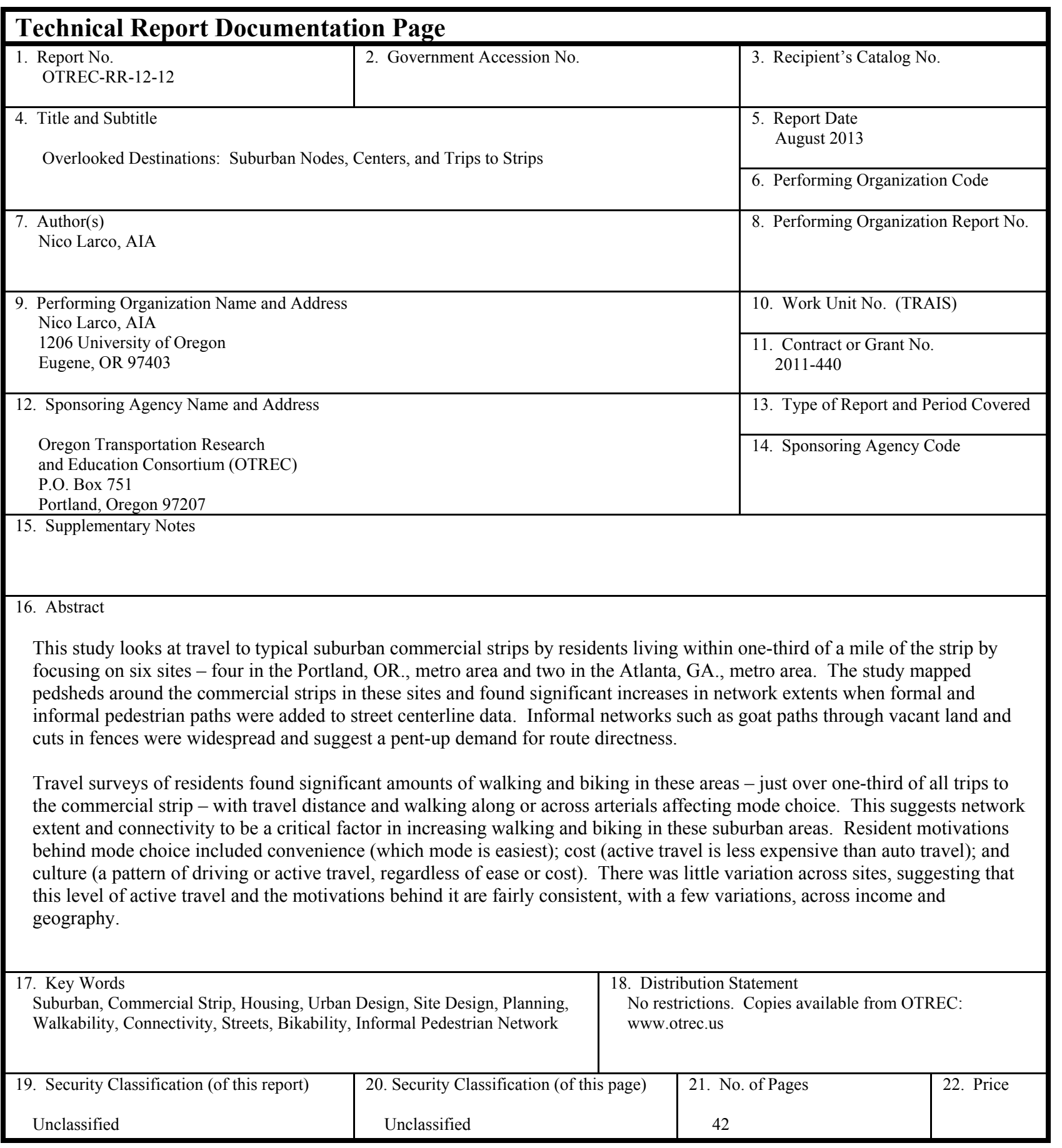




\section{ACKNOWLEDGEMENTS}

I would like to thank the Oregon Transportation Research and Education Consortium (OTREC) for funding this project. I would also like to thank Mike Hoglund and Crista Gardner at METRO, Jessica Engelmann at TriMet, and Sheila Lyons at the Oregon Department of Transportation for their willingness to partner on this project and their feedback as it moved forward. Schuyler Warren and Kristen Kelsey deserve a huge thanks for their continued assistance throughout the last year (and longer) on this work. Their contributions are to be found throughout this project. I want to thank Amanda West and Bethany Steiner from the Community Planning Workshop, who did the difficult job of organizing the seemingly endless logistics of administering the surveys. Jean Stockard deserves thanks for her gracious help with the data analysis for this work. I would also like to thank Marc Schlossberg, who has been a constant sounding board and support for this work and its dissemination. All of the merits of this project can be tied to people on this list while all of its shortcomings are squarely my own.

\section{DISCLAIMER}

The contents of this report reflect the views of the authors, who are solely responsible for the facts and the accuracy of the material and information presented herein. This document is disseminated under the sponsorship of the U.S. Department of Transportation University Transportation Centers Program in the interest of information exchange. The U.S. Government [assumes no liability for the contents or use thereof. The contents do not necessarily reflect the official views of the U.S. Government. This report does not constitute a standard, specification, or regulation. 


\section{TABLE OF CONTENTS}

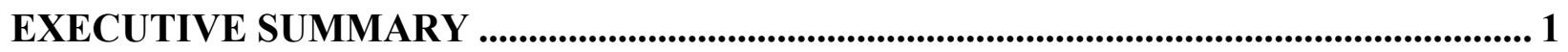

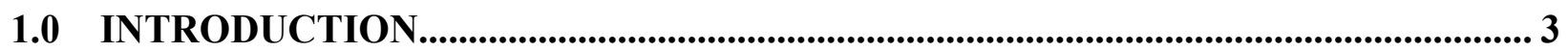

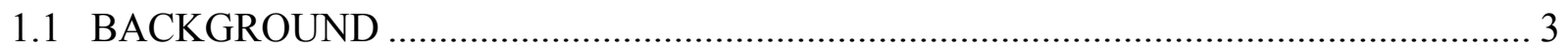

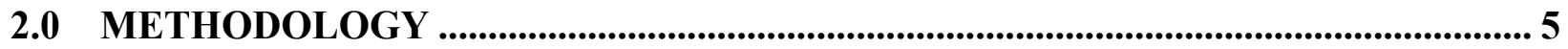

2.1 MAPPING PEDSHEDS - CENTERLINE, FORMAL AND INFORMAL PEDESTRIAN

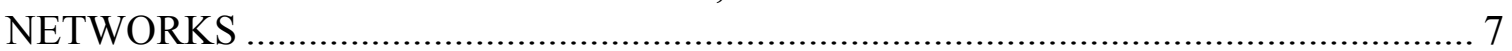

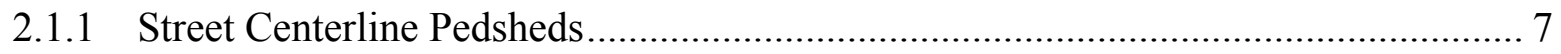

2.1.2 Formal Pedestrian Network Pedsheds (Formal Pedestrian Paths) ............................... 7

2.1.3 Complete Pedestrian Network Pedsheds (Including Informal Pedestrian Paths) ....... 8

2.1.4 Implications of the Prevalence of Informal Pedestrian Paths .................................. 10

2.1.5 Informal Pedestrian Paths - Good but not Great.................................................. 13

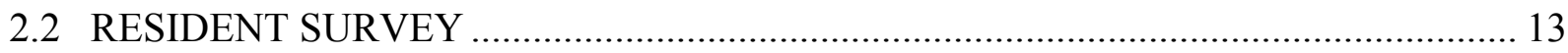

3.0 RESIDENT TRAVEL SURVEY FINDINGS AND DISCUSSION ................................ 15

3.1 TRAVEL MODES - ANALYZED BY NUMBER OF TRIPS ………………............. 15

3.2 TRAVEL MODES - ANALYZED BY HOUSEHOLDS ............................................. 16

3.3 ROUTE EFFECTS: DISTANCE AND ARTERIALS ……………............................ 17

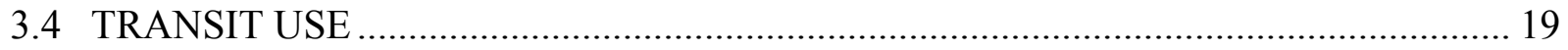

3.5 WHY WALK? - MOTIVATIONS FOR MODE CHOICE................................................ 21

3.5.1 Motivations for Driving ...................................................................................... 21

3.5.2 Motivations for Walking and Biking .................................................................... 22

3.5.3 Convenience, Cost and Culture: Motivations for Mode Choice................................ 23

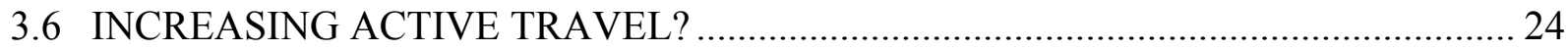

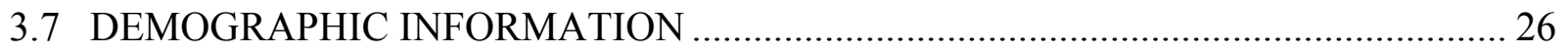

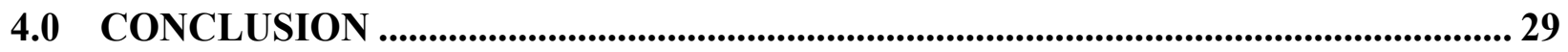

5.0 BIBLIOGRAPHY ................................................................................................................... 31 


\section{LIST OF TABLES}

Table 1: Study Site Description

Table 2: Pedshed Analysis Comparing Street Centerline Network and Combined Formal and

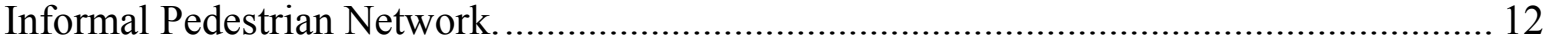

Table 3: Percent of Trips Per Week by Travel Mode ............................................................ 15

Table 4: Percent of Residents Using Travel Mode ................................................................ 16

Table 5: Route Interaction with Arterials and Resident Mode Choice ................................... 188

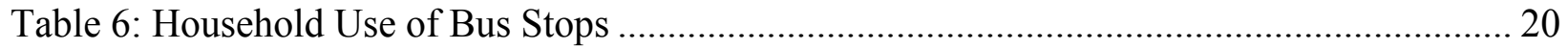

Table 7: Household Transportation Mode to Bus Stops ........................................................ 20

Table 8: Percent of Households Reporting Factors as Somewhat Important or Critical to Their

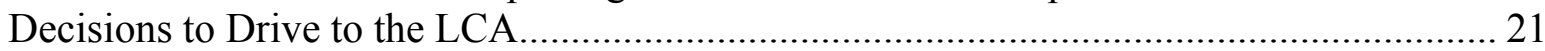

Table 9: Percent of Households Reporting Factors as Somewhat Important or Critical to Their

Decisions to Walk or Bike to the LCA ........................................................................... 22

Table 10: Would Residents Walk or Bike if it were Made Easier or More Convenient?............ 25

Table 11: Importance of Potential Improvements in Residents' Decision to Walk or Bike......... 25

Table 12: Percent of Residents Reporting Ease of Walking to Destination as Somewhat

Important or Critical to Their Decisions to Choose their Current Residence..................... 26

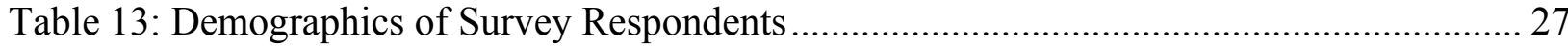

Table 14: Demographics of Survey Respondents and Census Comparison .............................. 28

\section{LIST OF FIGURES}

Figure 1: Examples of Informal Pedestrian Paths................................................................. 8

Figure 2: Informal Pedestrian Paths Around Oswego Town Center ....................................... 9

Figure 3: Oswego Town Center Informal Connection at the Rear of the Commercial Strip. ....... 9

Figure 4: Pedshed Analysis of Oswego Town Center ........................................................ 11

Figure 5: Pedshed Analysis of Portland Sites ..................................................................... 12

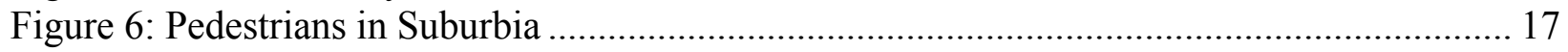

Figure 7: Histogram of Distance of Route From Residents' Homes to the Commercial Strip. ... 18 


\section{EXECUTIVE SUMMARY}

The dominance of auto trips and the lack of active forms of travel such as walking and biking in suburbia are topics that have recently garnered national and international attention. Research on this topic merges widespread concerns about health, the environment and economics with an investigation into the most prevalent form of development in the United States: suburbia. On the one hand, increasing active travel has been shown to improve health, reduce obesity rates and increase independence. On the other, the sprawling, disconnected, and single-use development pattern of suburbia is often considered antithetical to supporting active travel. This has led to calls for the wholesale redesigning of suburbia.

While completely remaking the suburbs into more compact, connected and mixed-use development patterns may be an appealing route to increasing active travel, given the tremendous extent of existing suburban development and the difficulty in implementing largescale redesigns, this is not a feasible means of doing so. This approach also overlooks the fact that certain areas of suburbia - specifically the areas around typical commercial strips - already host a significant amount of active travel and have the potential to support much more. Instead of completely remaking the suburbs, this study investigates the development around commercial strips, how urban form might be supporting active travel, and how these areas can be modified to further increase this type of travel.

This study identified six sites around typical suburban commercial strips (four in the Portland, OR., metro area and two in the Atlanta, GA., metro area). For each site we created detailed pedestrian-network GIS maps that compared network extents of maps that included only publicly available, street centerline data and maps that included pedestrian networks derived from aerial images and information garnered from "on-the-ground" site audits. The site audits unexpectedly revealed a large number of informal pedestrian paths across sites. These informal paths included shortcuts between parking areas and adjoining sidewalks, paths and breaks or gates in fences around the strip, and meandering trails through wooded or grassy areas around commercial developments.

The key findings from the mapping analysis are listed below:

- Informal pedestrian networks such as goat paths through wooded areas, cut-throughs, breaks in fences, and actual gates in fences are surprisingly widespread in these suburban areas. These informal networks suggest a strong pent-up demand for direct routes to suburban commercial strips.

- Consistent with previous research by others, mapping the pedestrian networks typically extended the quarter-mile walkable catchment area (pedshed) of each commercial strip. The addition of the formal and informal pedestrian networks to the street centerline calculations increased pedsheds by as much as $44 \%$ in one site. 
- Sites with smaller, formal network pedsheds had the greatest number of informal paths. The addition of these paths to the network effectively equalized pedsheds across all sites. This resulted in a sort of "gridding" of suburbia through the addition of informal pedestrian paths.

We also conducted a mail-in survey asking residents of our study sites how often they visited their local commercial area, what factors they considered in deciding their mode choice, and what changes to the built environment would affect their choices to walk or bike versus drive.

The key findings from the survey are listed below:

- There is a substantial amount of active travel to typical suburban strips, with over onethird of all trips to the local commercial strip being walking or biking trips.

- Twenty percent of households living within one-third of a mile of a suburban commercial strip report use of transit at the strip, and the vast majority of these residents walks or bikes to those transit stops.

- One-third of a mile was the median distance residents walked to the commercial strip and, overall, more than $65 \%$ of residents who walked travelled more than a quarter of a mile to the strip. This challenges planners' and urban designers' long-held belief about the quarter-mile limit on pedestrian travel distance.

- Residents are motivated by convenience (which mode is easiest), cost (active travel is less expensive than auto travel), and culture (a pattern of driving or active travel, regardless of ease or cost) in their mode choice to their local commercial strip. This suggests that increasing active travel could be achieved by increasing connectivity and making routes more direct as well as by media programs that help introduce walking and biking as affordable and viable forms of transport.

- Not surprisingly given the auto-oriented nature of typical suburban development, the most cited factor that would increase residents walking and biking in these sites was the provision of more and better places to walk and bike.

- Even in typical suburban settings, ease of walking or biking access to shops and restaurants factored strongly into residents' choices about where to live.

Although suburbia has often been thought of as an exclusively car-dependent area, this is simply not the case around typical suburban commercial strips. Active travel is widespread in these areas. In addition, where formal pedestrian connections don't exist, residents are consistently making informal, clandestine ones. Given the wide extent of these typical suburban commercial strips throughout the country, this study suggests that a large amount of active transportation might already exist in many areas of suburbia, with the potential to increase even more. 


\subsection{INTRODUCTION}

\subsection{BACKGROUND}

Planners have long vilified suburbs due to their low-density, single-use and auto-oriented layouts, as well as their much-heralded negative impact on health, the environment and economics. The sprawling, disconnected development pattern of typical suburbia has been countered by a call for compact, mixed-use and well-connected developments throughout the country (Ewing, 1997; Handy, 2005; Jabareen, 2006). Organizations such as the Congress for the New Urbanism have called for a complete redesign of our current suburbs along the lines of neotraditional development (Congress for the New Urbanism, 1996). A key element of this call, for many, is a desire to shift trips from auto travel to active modes such as walking and biking.

This is a commendable goal as the benefits of active travel are far-reaching. An increase in active travel has been correlated with improved health, lower body mass indexes, improved productivity in the form of lower sick days taken by individuals, and increased independence (Frank, Sallis et al., 2006). If active travel trips substitute auto trips and reduce vehicle miles travelled, the benefits extend to reductions of greenhouse gas emissions, the amount individuals spend on transportation and congestion, and an improvement in air quality.

Many of the studies related to active travel and development focus directly on the question of how the built environment affects mode choice, looking at the relationships between travel patterns and degrees of density, diversity, and the design or quality of travel routes (Cervero and Kockelman, 1997; Lee and Moudon, 2006; Forsyth, Hearst et al., 2008). Broad studies of suburban locations, however, found them largely devoid of active transport, primarily due to its seemingly inherent low density and dispersed, single-use land use patterns (Ewing, Schmid et al., 2003). If there is nowhere to go because of distances to destinations, no one will walk or bike.

But not all areas of suburbia are equal. Unlike much of suburbia, the suburban commercial strip is an instance of concentrated destinations often surrounded by a mix of single-family and medium-density multifamily housing. This alone creates a condition where many of the base criteria researchers have found necessary for active travel actually exist in suburbia. Although suburban commercial strips are typically considered to be auto-oriented many of their uses, such as grocery stores, pharmacies, banks and restaurants, also act as "pedestrian magnets." In addition, these commercial nodes are often served by transit - a potential pedestrian magnet in itself. It is this combination of density and "daily use" destinations that create a condition where active travel becomes viable in suburbia. There is somewhere to go and there are people living close enough to get there by foot or bike.

A number of studies have focused on these commercial strip areas and have shown a surprising amount of active transport actually occurring in suburbia (Hess, Moudon et al., 1999; Handy and Clifton, 2001; Larco, 2010; Larco, Steiner et al., 2011). Some of these studies counted pedestrians entering commercial strips in urban and suburban sites while others focused exclusively on the travel choices of suburban, multifamily-housing residents. Many of these 
studies showed that significantly more residents choose active modes of travel when they live in areas that are better connected to the commercial strip and therefore had reduced travel distances. Compact areas with more connected street networks correlate with increased physical activity (Saelens, Sallis et al., 2003; McGinn, Evenson et al., 2007); lower obesity rates (Booth, Pinkston et al., 2005); and increased walking and biking (Frank, Sallis et al., 2006).

Some of the studies on suburban travel also suggest that the quality of the residents' travel paths (speed of traffic, protection from traffic, etc.), as well as the quality of the suburban strip site design themselves, are important factors in residents' decisions to drive versus walk or bike. Interestingly, these studies have focused on utilitarian trips and not on work-related travel.

The potential for increasing active travel around suburban strips can have an exponential effect given the extent of these strips in the country. Currently, there are approximately 32,000 grocery-anchored neighborhood commercial centers in the country (International Council of Shopping Centers, 2010). Our research using a commercial developer database found that it is not uncommon to have 1,200 residences within a quarter mile of suburban commercial strips, and that in Portland - one of our study areas - suburban commercial strips have an average of nearly 900 housing units within a quarter mile of them (Unpublished research by the author using CoStar Realty Information Inc., 2010). Given this, impacting the travel preferences of residents living near suburban commercial strips can have a significant cumulative affect across the country and can literally affect millions of trips per week.

The current study builds on this previous work and investigates the travel behavior of residents living within walking distance of suburban, neighborhood commercial strips in the Portland and Atlanta metro areas. Specifically, this study looks at how often residents travel to their local commercial centers, what modes they choose, the factors they consider when deciding on those modes, and what changes would be most salient to their considering active modes of transport for these trips. As part of this study, we also analyzed the vehicular and pedestrian networks through GIS models of our case study sites. 


\subsection{METHODOLOGY}

In this study we focused on the Portland and Atlanta metro areas for our case study sites. The intention was to find typical suburban sites in diverse areas so that the study could be somewhat representative of conditions found across the country. While both of these metro areas include substantial suburban development, they represent diverse geographic locations, diverse climates, and diverse cultures of auto use. In a national ranking of the 40 largest metro areas in the country, Atlanta ranks $6^{\text {th }}$ in daily vehicle miles traveled per resident while Portland ranks $35^{\text {th }}$ (Federal Highway Administration, 2008). We identified case study sites within these metro areas based on spatial criteria, qualities of the retail destinations, and demographic criteria. Given these diverse site criteria, we attempted to maintain as much parity as possible between the sites.

In terms of spatial criteria all sites were in suburban locations - defined as existing outside of central business districts, with auto-oriented commercial centers, single-use zoning, extensive parking areas in front of commercial space, and predominantly residential uses surrounding the commercial centers. As is typical of suburban commercial centers, sites needed to be located along arterials and, in order to maintain parity between sites, had to have full or near-full buildout of adjacent parcels.

As the purpose of this study was to analyze residents' travel choices and our intention was to select sites that were typical of suburban development, it was necessary that each site contain relatively standard and common destinations. In terms of retail criteria, we focused on sites fitting the International Council of Shopping Center's (ICSC's) definition of "Neighborhood Centers." These centers are "designed to provide convenience shopping for the day-to-day needs of consumers in the immediate neighborhood," and have a catchment area of approximately three miles (ICSC, 1999; ICSC, 2010). By ICSC's calculations, there are approximately 32,000 of these centers throughout the country. This offers a wide spectrum of potential sites, but also points to the magnitude of this condition and how localized changes can potentially multiply across sites with profound effects.

To maintain parity between sites, we selected neighborhood centers that had a grocery-store anchor with a minimum of 40,000 square feet of gross leasable space in addition to a range of other typical stores that might act as pedestrian magnets, such as banks, restaurants and dry cleaners (definition of "Pedestrian Magnets" came from the U.S. Green Building Council, 2008; Forsyth, 2012). All selected sites had between 100,000-175,000 square feet of total gross leasable space except for one site in Atlanta, Plantation Point, which had approximately 63,000 square feet of occupied space but included a rich range of pedestrian magnets.

The median income level of the residents surrounding the commercial center was the primary demographic criteria that we considered in the site selection. We intentionally included a range of income levels in each of the metro areas in order to see how this affected overall rates of walking and biking. Other demographic factors (such as family type and car-ownership rates) were difficult to control at the site-selection level and instead were considered individually at the survey-response level. 
To generate an initial list of potential case study sites using the criteria described above, we used CoStar, a commercial real estate-focused data compiler. We narrowed this initial list by eliminating sites that had other commercial development adjacent to or across the street from the site in question, as this might confound survey clarity and hence the results. We also eliminated any expressly master-planned New Urbanist or transit-oriented development, as these types of sites are not typical of suburban development across the country. Further culling of the list was done by reviewing aerial maps of the sites and eliminating ones that included interstates or railroads within a quarter mile, had major topographical obstacles, or included exclusively single-family or multifamily housing around them. To simplify site comparison, from this smaller list we selected sites that were on a single arterial (as opposed to the intersection of two arterials).

We then shared the resulting list with planning and transportation professionals in each metro area, and they helped identify any unforeseen, confounding conditions in the sites and the sites they considered to be representative of typical suburban development in the area. Through this process, some sites were eliminated due to unusually high crime rates, the inclusion of a large amount of assisted living facilities, or current high vacancy rates.

The final list of sites included four sites in Portland and four in Atlanta. Two of the sites in Atlanta were eliminated later in the study due to extremely low survey-response rates and are therefore not included in our analysis (response rates are described in more detail below). We believe this low response rate to have been largely due to language issues. The final six sites used in the study are described in Table 1.

Table 1: Study Site Description

\begin{tabular}{|c|c|c|c|c|c|c|c|c|}
\hline & Site Name & $\begin{array}{l}\text { Gross } \\
\text { Leasable } \\
\text { Area } \\
\end{array}$ & $\begin{array}{l}\text { Number } \\
\text { of Stores }\end{array}$ & $\begin{array}{l}\text { Type of } \\
\text { Anchor } \\
\end{array}$ & $\begin{array}{l}2010 \text { Median } \\
\text { Household } \\
\text { Income* }\end{array}$ & $\begin{array}{l}\text { Single- } \\
\text { Family } \\
\text { Housing } \\
\text { Units++ }\end{array}$ & $\begin{array}{l}\text { Multifamily } \\
\text { Housing } \\
\text { Units++ } \\
\end{array}$ & $\begin{array}{l}\text { Total } \\
\text { Housing } \\
\text { Units++ } \\
\end{array}$ \\
\hline \multirow{4}{*}{ 营 } & $\begin{array}{c}\text { Oswego } \\
\text { Town } \\
\text { Center } \\
\end{array}$ & $105,062 \mathrm{SF}$ & 36 & Supermarket & $\$ 83,318.00$ & 505 & 835 & 1,340 \\
\hline & $\begin{array}{c}\text { Greenway } \\
\text { Town } \\
\text { Center } \\
\end{array}$ & $139,339 \mathrm{SF}$ & 27 & $\begin{array}{l}\text { Supermarket/ } \\
\text { Pharmacy }\end{array}$ & $\$ 65,226.00$ & 810 & 1,336 & 2,146 \\
\hline & $\begin{array}{l}\text { Meadow- } \\
\text { land }\end{array}$ & $163,819 \mathrm{SF}$ & 19 & Supermarket & $\$ 54,340.00$ & 572 & 1,443 & 2,015 \\
\hline & $\begin{array}{c}\text { San Rafael } \\
\text { Shopping } \\
\text { Center }\end{array}$ & $142,495 \mathrm{SF}$ & 11 & Supermarket & $\$ 55,658.00$ & 978 & 326 & 1,304 \\
\hline \multirow{2}{*}{$\frac{\pi}{\stackrel{E}{E}}$} & $\begin{array}{c}\text { Plantation } \\
\text { Pointe }\end{array}$ & $63,200 \mathrm{SF}$ & 21 & Supermarket & $\$ 61,426.00$ & 393 & 1,967 & 2,360 \\
\hline & $\begin{array}{l}\text { Candler- } \\
\text { McAfee }\end{array}$ & $175,272 \mathrm{SF}$ & 26 & Supermarket & $\$ 45,394.00$ & 593 & 56 & 649 \\
\hline
\end{tabular}

* Estimated for households within a 1-mile radius of LCA. CoStar.

++ Counts include all units within 1/3 mile of the commercial strip 'as the crow flies'.

Source: CoStar and GIS Data from Municipalities/Counties 


\subsection{MAPPING PEDSHEDS - CENTERLINE, FORMAL AND INFORMAL PEDESTRIAN NETWORKS}

For this study we were interested in analyzing the relative connectivity of different sites. Our primary measure for connectivity in this study was the site pedestrian catchment area or "pedshed" (Western Australia Planning Commission, 2000; Porta and Renne, 2005; Chin, Van Niel et al., 2008). The pedshed in this study is a measure of the overall area and number of residences that are located within one-third of a mile from the commercial center as measured by the travel distance in the street network. This is a subset of the total area and number of units located within one-third of a mile radius around the commercial center. Pedsheds are larger in well-connected sites, as they offer more direct routes between the focal point and surrounding development. For our purposes, the focal point was the commercial strip parcel.

We did three iterations of pedshed analysis: one using widely available and used GIS street centerline data; one using pedestrian network maps with formal pedestrian paths we identified from a combination of the centerline data, aerials and onsite audits; and one that included the fairly widespread informal pedestrian connections we unexpectedly found through site audits. Each of these iterations is described below in more detail.

\subsubsection{Street Centerline Pedsheds}

For the street centerline pedshed map, we used GIS street network shapefiles obtained from governing agencies at each site (Metro in Portland and Dekalb and Cobb counties in Georgia). Because the commercial strips are large parcels, we used a modified approach where we created base points at each of the vehicular or pedestrian entry points to the neighborhood center as the focus points. Using street analyst in ArcGIS, we measured a one-third-mile street network distance from each of these points. All of the parcels that touched a street within this distance were considered part of that site's pedshed resident count. In this calculation, we used the onethird-mile distance instead of the more commonly considered quarter-mile walking distance, as our pilot studies indicated the longer distance was more accurate in capturing actual resident travel behavior.

\subsubsection{Formal Pedestrian Network Pedsheds (Formal Pedestrian Paths)}

The Formal Pedestrian Network Pedsheds included all of the formalized (paved or improved) pedestrian paths within one-third of a mile of the commercial strip. We built these maps from scratch in GIS using recent orthographic aerial photos, Google Street View, Bing Maps, and a Trimble GPS unit during on-the-ground site audits. The bulk of these networks were built using the aerial photos and online maps/streetview with some areas - typically occluded by foliage in the aerials - finalized only after on-site audits.

For the on-the-ground site audits, one to three researchers visited each site and travelled the pedestrian network by foot or on bike. Using base maps of the street and pedestrian network, we recorded additional formal and informal paths and connections that were not part of our street network data and not legible through the analysis of aerial photographs of the case study sites. 
The formal pedestrian networks were much more intensive than the street centerline maps. They typically included paths on both sides of the street as well as pedestrian paths (and vehicular paths that could be used by pedestrians) in larger multifamily developments, parks and commercial parcels. These maps also included a few formal, short and exclusively pedestrian paths that were publicly owned and provided cut-through between blocks of the street network.

\subsubsection{Complete Pedestrian Network Pedsheds (Including Informal Pedestrian Paths)}

To our surprise, in addition to assisting with the identification of formal pedestrian networks, the site audits also revealed a large number of informal, or worn, goat paths that largely expanded the connectivity of the formal pedestrian or street network. These paths included brief shortcuts that linked parking areas to sidewalks, a large number of breaks or gates in fences, and longer meandering trails through wooded areas around commercial developments (see figures 1,2 and 3). Surprisingly, the paths were equally pervasive through commercial property, vacant land, around multifamily housing, and through private single-family yards.
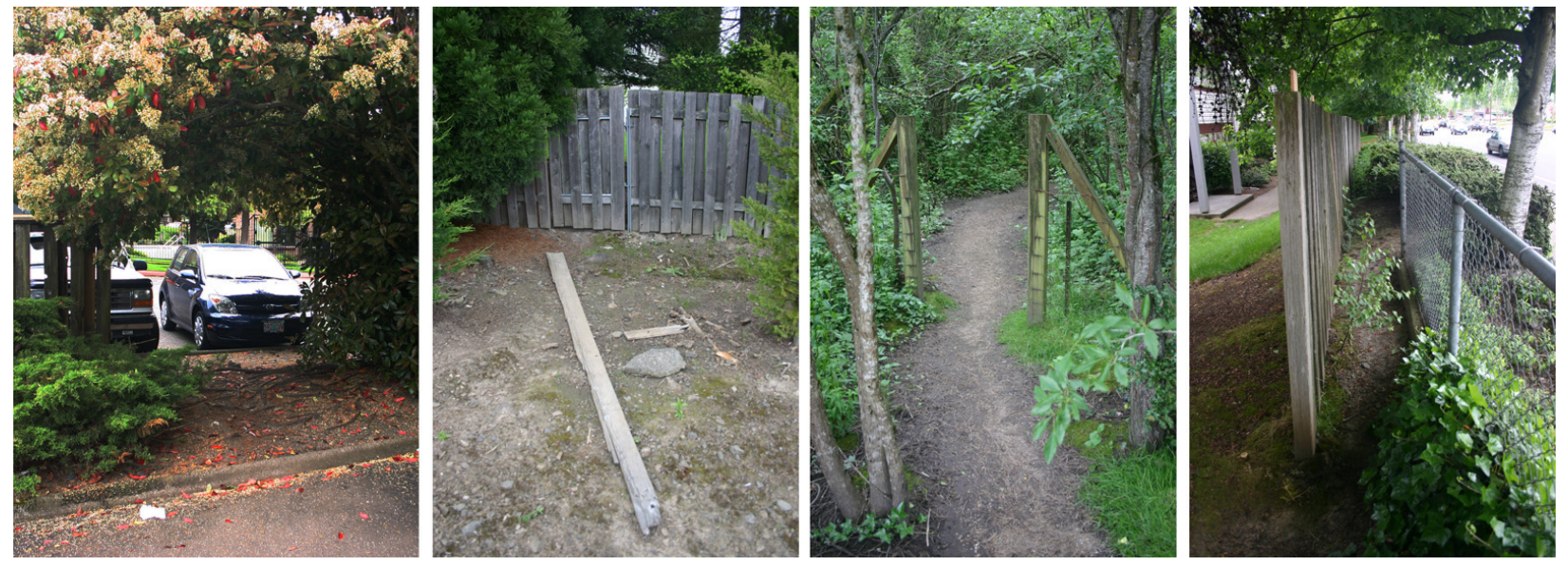

Figure 1: Examples of Informal Pedestrian Paths: (From left to right) A torn-down section of fence behind a commercial strip that connects to multifamily housing; a gate in a private fence with a wood plank that provides footing on wet days; a more established and maintained path through a wooded area that connects to a driveway and then a public street; and a worn path between fences connecting multifamily housing to an arterial. 


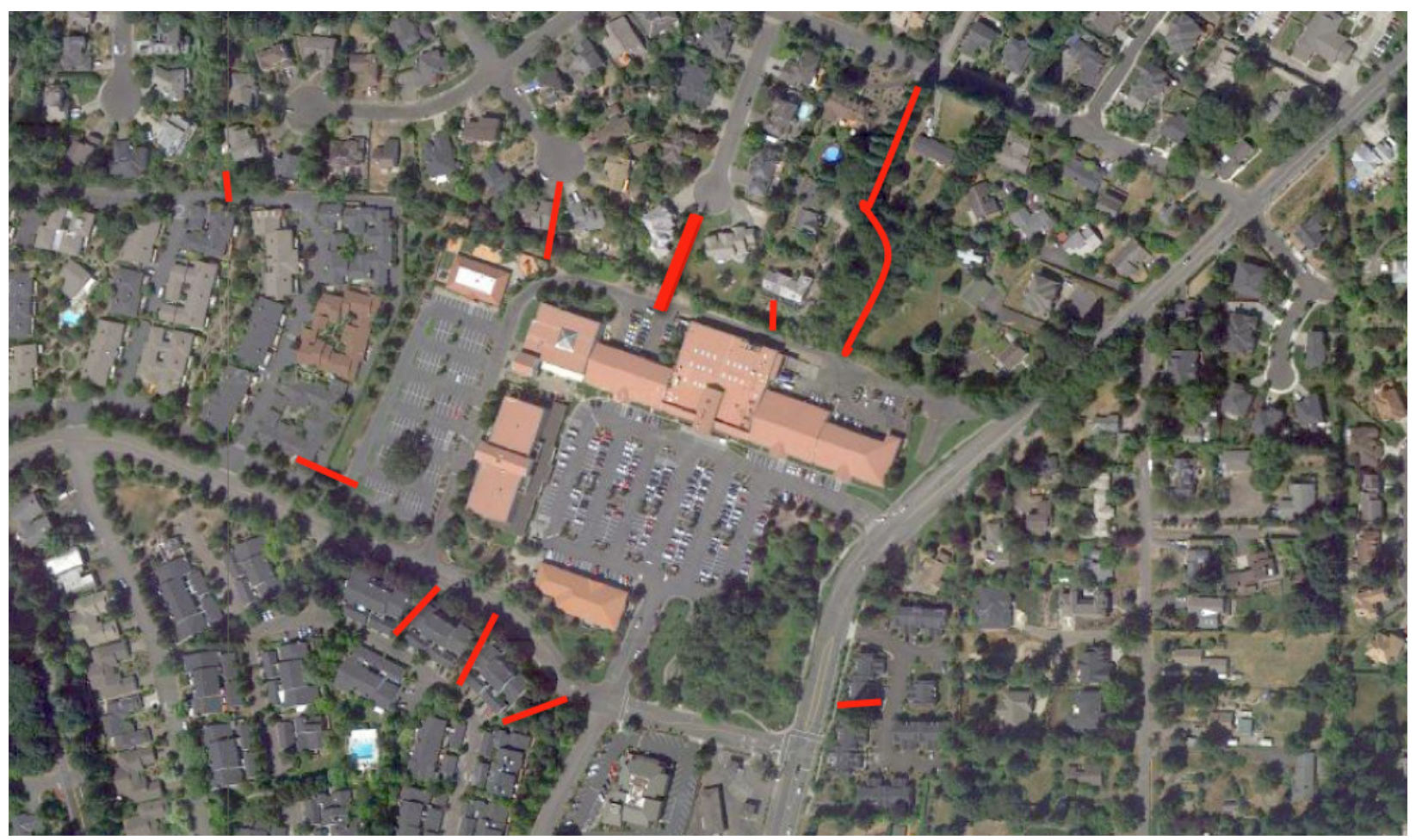

Figure 2: Informal Pedestrian Paths Around Oswego Town Center: Some of the paths are shortcuts into multifamily complexes, some connect through private land to the street network, and some are simply short paths and gates that connect only to a single private residence.

Paths differed in their amount of oversight and maintenance, with some being fairly littered and uneven while others were better kept, relatively clear of obstacles, and with relatively even surfaces. None of the paths had lighting associated with them. Some were literally cuts in fences, pushed down fences, or pulled back fences with well-worn paths leading directly through them. During our site audits we saw a range of residents using these paths - everything from children to more elderly residents, residents with shopping bags, and residents seemingly on their way to or from work.

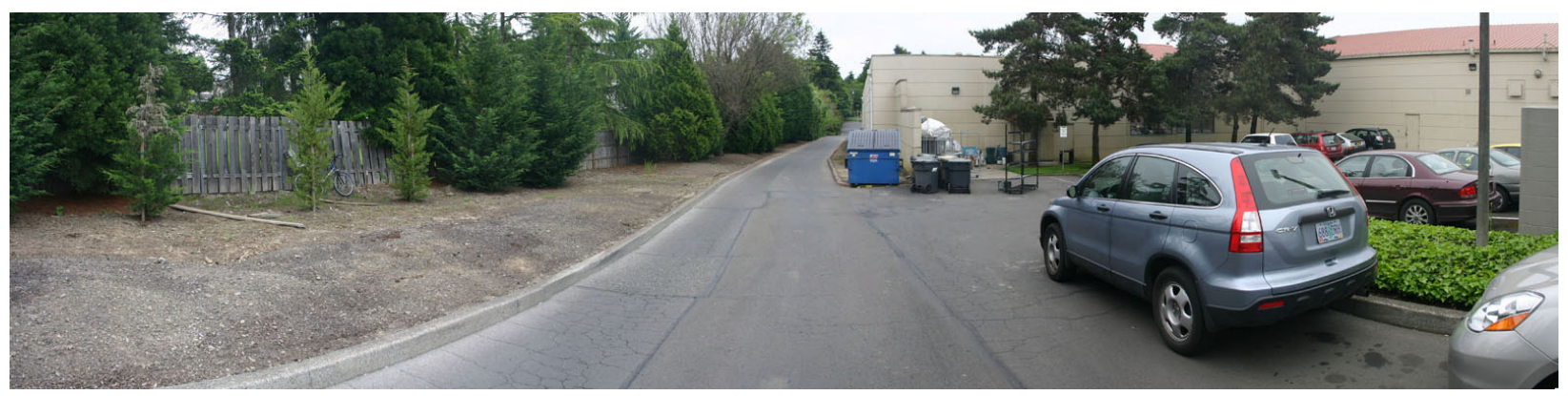

Figure 3: Oswego Town Center Informal Connection at the Rear of the Commercial Strip: Notice the wooden plank on the left that leads to a gate within the fence. This gate opens onto a single-family home's private yard that is open to the road beyond. Owners of that yard reported that they allow neighbors and friends to use their property as a shortcut to the commercial strip. 
Although the sample size of six case study sites was arguably small for largely generalizable observations, in our study sites we were surprised to find no correlation between income and the prevalence of informal paths. Both high-income and lower-income areas had substantial informal paths and the area with the largest number of informal connections and, hence, the largest increase in its pedestrian catchment area was Lake Oswego, the most affluent of all our case study sites. Paths situated within single-family home parcels were also not correlated with income, as we found these in a number of both higher- and lower-income sites.

\subsubsection{Implications of the Prevalence of Informal Pedestrian Paths}

The existence and extent of these informal networks is a significant finding in itself and shifts two common conceptions of suburbia. First, whereas suburbia is typically considered to foster limited desire for pedestrian utilitarian trips to commercial centers, these paths signal a substantial desire of residents to have direct (or more direct) non-motorized access to commercial destinations. Faced with fences, private property and unwelcoming backs of buildings, residents still choose to blaze direct and clandestine pedestrian paths to commercial centers.

The second shift in the common conceptions of suburbia is that it may not be as spatially isolating and disconnected as street network representations of suburban areas suggest. Large access shadows (areas that are disconnected from their surrounding development) may actually hold intense informal networks that equalize the actual accessibility to a site. For example, the extents and ubiquitous nature of these informal paths completely altered the pedshed of our case study sites. Predictably, the sites that had the smallest pedshed - in other words, the most limited access and most extensive barriers between residences and commercial destinations - were the sites that had the most extensive informal networks. In fact, as we calculated the Complete Pedestrian Network Pedshed (that included informal paths) for all of the sites, what had originally seemed to be a large gradation of connectivity between the sites when only looking at street centerline data suddenly became a fairly narrow range of connectivity (see Table 2 and figures 4 and 5). Sites' pedshed acreages increased by an average of 19\%, with Plantation Pointe in Atlanta increasing $44 \%$. The number of households that were within the pedshed also increased dramatically, with an average $10 \%$ increase across sites and a $20 \%$ increase in Greenway Town Center. 

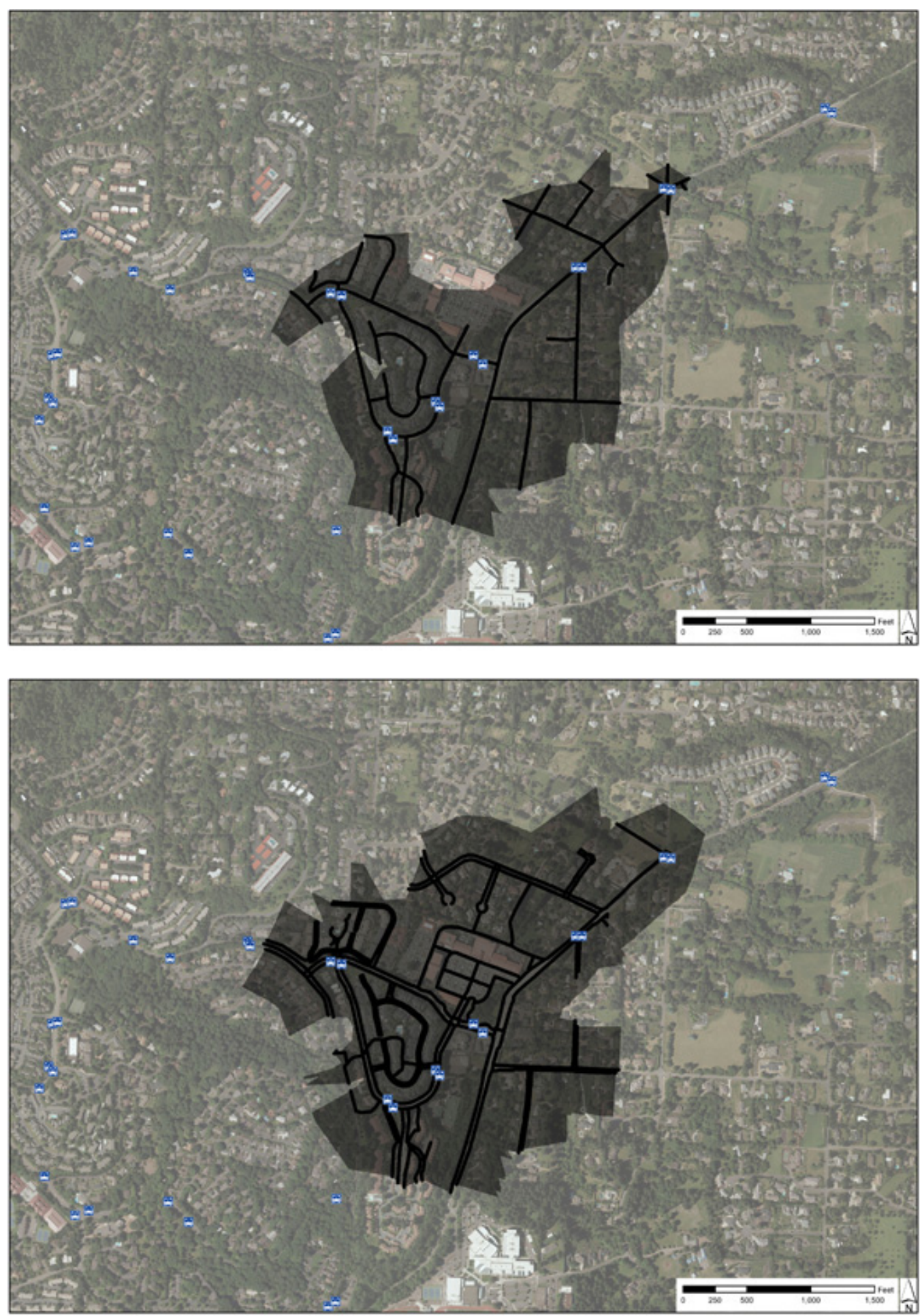

Figure 4: Pedshed Analysis of Oswego Town Center: The top image is a street centerline pedshed (114 acres) and the bottom image is the formal and informal pedestrian network pedshed (147 acres). The formal and informal connections increase the pedshed by $28.9 \%$. 

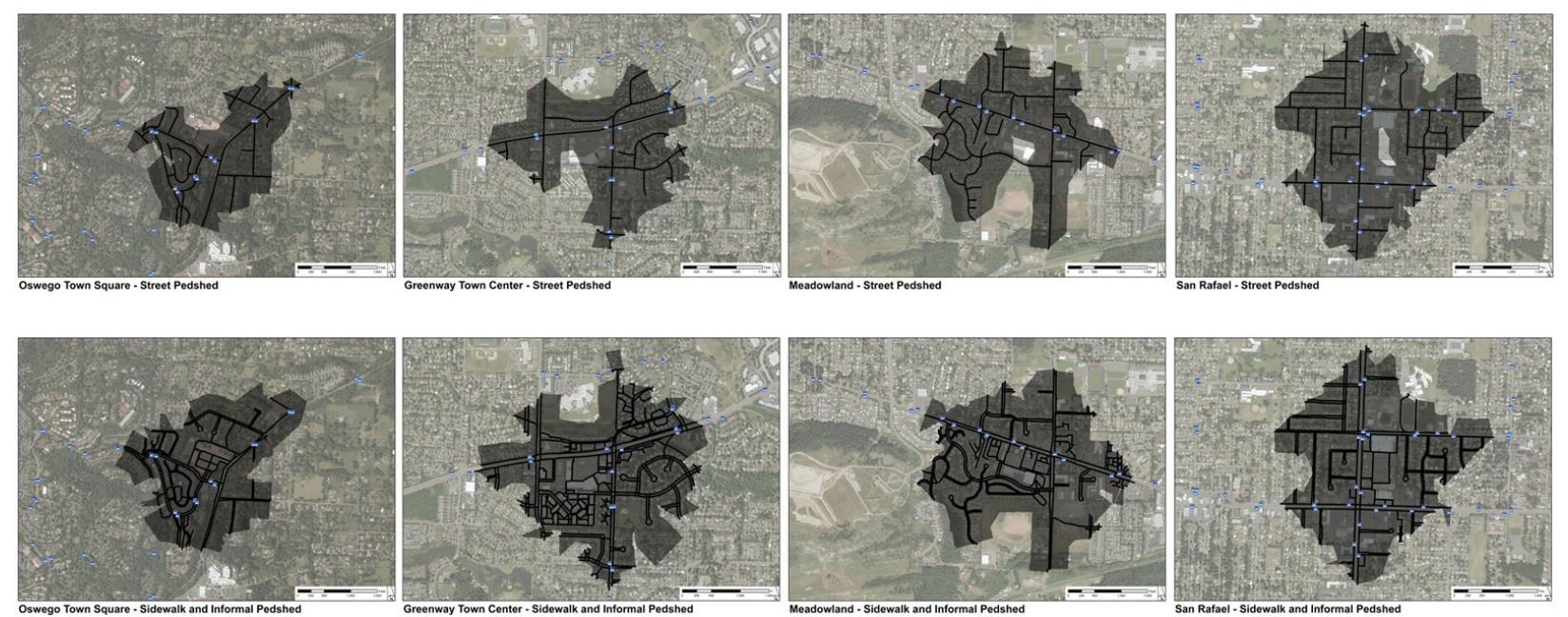

Figure 5: Pedshed Analysis of Portland Sites: The top images are of pedsheds of the street centerline network. Bottom images are the same sites, but showing the formal and informal pedestrian network pedshed. Notice the relatively similar size of the pedsheds once the formal and informal pedestrian networks are taken into account.

Some of this increase in units within the pedshed is due to the tremendous increase in accessibility these informal paths give to mid- to high-density multifamily housing located adjacent to the commercial strips in some sites. These housing developments often do not have direct, formal pedestrian connections to adjacent commercial strips and instead rely on the formal vehicular connection points, which are often far away from the commercial center and along the arterial.

Table 2: Pedshed Analysis Comparing Street Centerline Network and Combined Formal and Informal Pedestrian Network.

\begin{tabular}{|c|c|c|c|c|c|c|c|}
\hline & \multirow[b]{2}{*}{ Site Name } & \multicolumn{2}{|c|}{$\begin{array}{c}\text { Street Centerline } \\
\text { Network } \\
\text { 1/3-Mile Pedshed } \\
\end{array}$} & \multicolumn{2}{|c|}{$\begin{array}{c}\text { Complete Pedestrian } \\
\text { Network 1/3-Mile } \\
\text { Pedshed (Including } \\
\text { Formal and Informal } \\
\text { Ped. Paths) } \\
\end{array}$} & \multicolumn{2}{|c|}{$\%$ Increase in Pedshed } \\
\hline & & Acreage & Households & Acreage & Households & Acreage & Households \\
\hline \multirow{4}{*}{ م } & Oswego Town Center & 114 & 630 & 147 & 654 & $28.9 \%$ & $3.8 \%$ \\
\hline & Greenway Town Center & 144 & 1,261 & 186 & 1,517 & $29.2 \%$ & $20.3 \%$ \\
\hline & Meadowland & 177 & 1,310 & 203 & 1,372 & $14.7 \%$ & $4.7 \%$ \\
\hline & $\begin{array}{c}\text { San Rafael Shopping } \\
\text { Center }\end{array}$ & 196 & 710 & 192 & 701 & $-2.0 \%$ & $-1.3 \%$ \\
\hline \multirow{2}{*}{ 吾 } & Plantation Pointe & 126 & 951 & 182 & 1,081 & $44.4 \%$ & $13.7 \%$ \\
\hline & Candler-McAfee & 164 & 246 & 185 & 289 & $12.8 \%$ & $17.5 \%$ \\
\hline
\end{tabular}


In addition to the pedshed extent metric, the informal connections are also reducing the distance residents have to travel to their local commercial center by creating more direct routes. The informal networks are, in effect, "gridding the suburbs" to some extent, making seemingly disconnected areas look more like the connectivity of gridded well-connected areas.

\subsubsection{Informal Pedestrian Paths - Good but not Great...}

It should be noted that informal paths are not equal to formal ones and do not represent a clean, equivalent extension of the pedestrian network. While they do increase connectivity, these paths often tread (potentially uncomfortably) on private property. They are rarely patrolled, which may cause security concerns for residents willing to use these more direct connections. Because they are often on private property, they also have the potential to be closed down at any point in time. We heard evidence of this during our site audits from residents who reported a closure by someone who had recently moved into the neighborhood and were uncomfortable with the large amounts of youth using the connection and leaving trash in the area.

While these paths seem to be getting substantial use, we hypothesize that this may be for a limited demographic. It is hard to pass through these areas of uneven terrain if you are elderly or with a stroller. In addition, because of the overgrown nature of much of the planting around these paths as well as the lack of lighting and "eyes on the street," these areas appear more dangerous than a formal path, especially at night. This could be a serious disincentive or barrier for more vulnerable populations.

These paths also present a potential liability issue for commercial and private property owners. If a resident is injured or harmed on one of these paths, through malicious behavior or simply a lack of site maintenance, it is unclear who holds the liability. If the liability is a large issue in these cases, it may be that the clandestine nature of the paths might be exactly what is making their existence possible.

The existence and extent of these informal paths could be a striking addition to the understanding of the pedestrian networks in suburban areas and their "design," genesis and use (who is using it, when and why) are all areas of research that require further study.

\subsection{RESIDENT SURVEY}

In order to understand the travel habits of suburban residents living near commercial centers, we developed the Resident Travel Survey and sent it to residents of the case study sites. The survey asked questions about residents' travel habits, how they choose their transportation modes, and barriers they saw to walking and biking. The survey consisted of 29 questions divided into six topic areas: transportation modes and frequency; transportation choices; ease of walking and biking; housing choice; demographic information; and a final section consisting of a mapping exercise. The first page of the survey included instructions along with an aerial map of the local commercial area that was the survey's focus. The map included the address of the commercial 
center, a dotted outline of its extents, the names of major roads, a list of main stores, and transit stops locations.

We initially sent 200 surveys to addresses within each site purchased from a direct-mail database company. Due to typical address discrepancies, the survey was received by a total of 1,112 residents in the six sites we included in the full study. We sent the surveys out in the last week in March and first week in April of 2011 and used standardized survey distribution strategies, including an introductory postcard, a survey mailing, and a follow-up postcard. Similar to previous survey studies we had done, sites outside of our home state had lower response rates than those within the state. To mitigate this, we mailed a second survey to residents of the Atlanta sites in order to increase response rates.

We received a total of 274 surveys returned by residents - 197 in the four Portland sites and 77 in the two Atlanta sites. This represented a 26.7\% return rate for the Portland sites and a 20.5\% return rate for the Atlanta sites. These rates are within the expected norm for this type of survey. Survey findings are discussed in Section 3.0.

All study sites were surveyed simultaneously to avoid differences in weather, fuel costs and day length. The survey period had an even mix of sun and rain, with daytime temperatures typically ranging between the mid-40s up into the $60 \mathrm{~s}$ in Portland and the mid-40s into the $80 \mathrm{~s}$ in Atlanta. In general, Portland has mild but wet winters, a mix of wet and dry springs and falls, and mild, dry, and pleasant summers, making walking and biking feasible throughout the year. Atlanta is a warmer and more humid climate, where the heat in summer is occasionally a barrier to walking and biking. 


\subsection{RESIDENT TRAVEL SURVEY FINDINGS AND DISCUSSION}

The resident travel survey was divided into the following six sections: travel modes, factors influencing transportation choices, ease of walking and biking, housing choices, demographic information, and a mapping exercise. The results from each of these sections are discussed below.

As discussed previously, connectivity differences between the study sites was found to be minimal after considering informal pedestrian networks. For this reason, the survey analysis did not focus on finding statistically significant differences between the sites (as had been originally proposed in this research). The data for each individual site is listed below for the interest of readers, but the majority of the discussion is focused on the overall combined responses of all surveys.

\subsection{TRAVEL MODES - ANALYZED BY NUMBER OF TRIPS}

The first three survey questions asked residents to estimate the total number of driving, walking and biking trips they made to their local commercial areas (LCA) in a typical week. The LCA was defined for residents through an aerial map showing the area, nearby streets, names of stores in the LCA, and the border of what we considered to be each site's LCA. We defined walking as including wheelchair use and biking as well as any other non-motorized transportation with wheels (bicycle, skateboard, rollerblades, etc.). The results of these questions are shown in Table 3.

Table 3: Percent of Trips Per Week by Travel Mode

\begin{tabular}{l|c|c|c|c|c|c|c}
\hline \multirow{2}{*}{} & & \multicolumn{4}{c|}{ Portland } & \multicolumn{2}{c}{ Atlanta } \\
\cline { 3 - 9 } & OVERALL & $\begin{array}{c}\text { Oswego } \\
\text { Town } \\
\text { Center }\end{array}$ & $\begin{array}{c}\text { Greenway } \\
\text { Town } \\
\text { Center }\end{array}$ & $\begin{array}{c}\text { San } \\
\text { Rafael } \\
\text { land }\end{array}$ & $\begin{array}{c}\text { Shopping } \\
\text { Center }\end{array}$ & $\begin{array}{c}\text { Plantation } \\
\text { Pointe }\end{array}$ & $\begin{array}{c}\text { Candler- } \\
\text { McAfee }\end{array}$ \\
\hline Driving & $65 \%$ & $67 \%$ & $63 \%$ & $64 \%$ & $71 \%$ & $61 \%$ & $66 \%$ \\
\hline Walking & $29 \%$ & $32 \%$ & $32 \%$ & $21 \%$ & $26 \%$ & $31 \%$ & $30 \%$ \\
\hline Biking & $5 \%$ & $2 \%$ & $4 \%$ & $14 \%$ & $4 \%$ & $7 \%$ & $4 \%$ \\
\hline Walking or & $35 \%$ & $34 \%$ & $37 \%$ & $36 \%$ & $29 \%$ & $39 \%$ & $34 \%$ \\
\hline Biking & 258 & 62 & 37 & 32 & 50 & 49 & 28
\end{tabular}

Contrary to popular perceptions as well as studies regarding mode choice in suburbia (Ewing, Schmid et al., 2003), residents across all sites reported a substantial amount of active transportation use. Just over a third (35\%) of all trips to the LCA were either biking or walking trips. These results suggest that even though suburbia is largely auto-oriented, it is not exclusively auto-dominated. Even in suburbia, the basic criteria needed to generate active travel are amply present in areas surrounding typical neighborhood commercial centers. 
In comparing across sites, it is interesting to note that there is a fairly narrow range of variation in the active travel-mode split (29\% to 39\%) that did not reach significance between any sites. This points to three issues. First, income of the overall area does not seem to be correlated with mode choice. Both the affluent and less-affluent areas reported similar rates of active travel. Second, even though Portland and Atlanta are arguably two extremes in the spectrum of overall auto use and what we might call a "pedestrian and bike culture," they show very similar mode splits. While this study is limited in its scale, it suggests that similar results would be found in cities that lie between these two extremes. This is an area for further study.

Third, these results complicate our initial hypothesis regarding mode splits of wellconnected/less-connected sites. They suggest that the expanded pedestrian network created by the informal connections described previously might truly be equalizing the overall connectivity in these sites and, hence, minimizing mode split differences - a true "gridding of suburbia."

\subsection{TRAVEL MODES - ANALYZED BY HOUSEHOLDS}

If we look at this same data in relation to households instead of trips, we find that $41 \%$ percent of households have residents who are walking or biking to their LCA in a typical week. This number approaches or exceeds $50 \%$ in a few of the sites. Even in suburbia a large number of residents see active travel as a viable form of transport for local, utilitarian trips. In fact, onequarter of households are using active travel for half or more of their trips to the LCA. For these households, walking and biking are on par or even more commonly used than the automobile as the transportation mode to the LCA. This suggests that active travel is not just a fringe travel mode, but is instead well used for local utilitarian trips by many residents in suburbia.

Table 4: Percent of Residents Using Travel Mode

\begin{tabular}{|c|c|c|c|c|c|c|c|}
\hline & \multirow[b]{2}{*}{ OVERALL } & \multicolumn{4}{|c|}{ Portland } & \multicolumn{2}{|c|}{ Atlanta } \\
\hline & & $\begin{array}{c}\text { Oswego } \\
\text { Town } \\
\text { Center } \\
\end{array}$ & $\begin{array}{c}\text { Greenway } \\
\text { Town } \\
\text { Center } \\
\end{array}$ & $\begin{array}{l}\text { Meadow- } \\
\text { land }\end{array}$ & $\begin{array}{c}\text { San } \\
\text { Rafael } \\
\text { Shopping } \\
\text { Center } \\
\end{array}$ & $\begin{array}{c}\text { Plantation } \\
\text { Pointe }\end{array}$ & $\begin{array}{l}\text { Candler- } \\
\text { McAfee }\end{array}$ \\
\hline Ever Walk/Bike & $41 \%$ & $47 \%$ & $51 \%$ & $28 \%$ & $42 \%$ & $33 \%$ & $46 \%$ \\
\hline $\begin{array}{l}\geq 50 \% \\
\text { Walk/Bike Trips }\end{array}$ & $25 \%$ & $26 \%$ & $30 \%$ & $25 \%$ & $24 \%$ & $24 \%$ & $21 \%$ \\
\hline $\mathrm{n}=$ & 258 & 62 & 37 & 32 & 50 & 49 & 28 \\
\hline
\end{tabular}



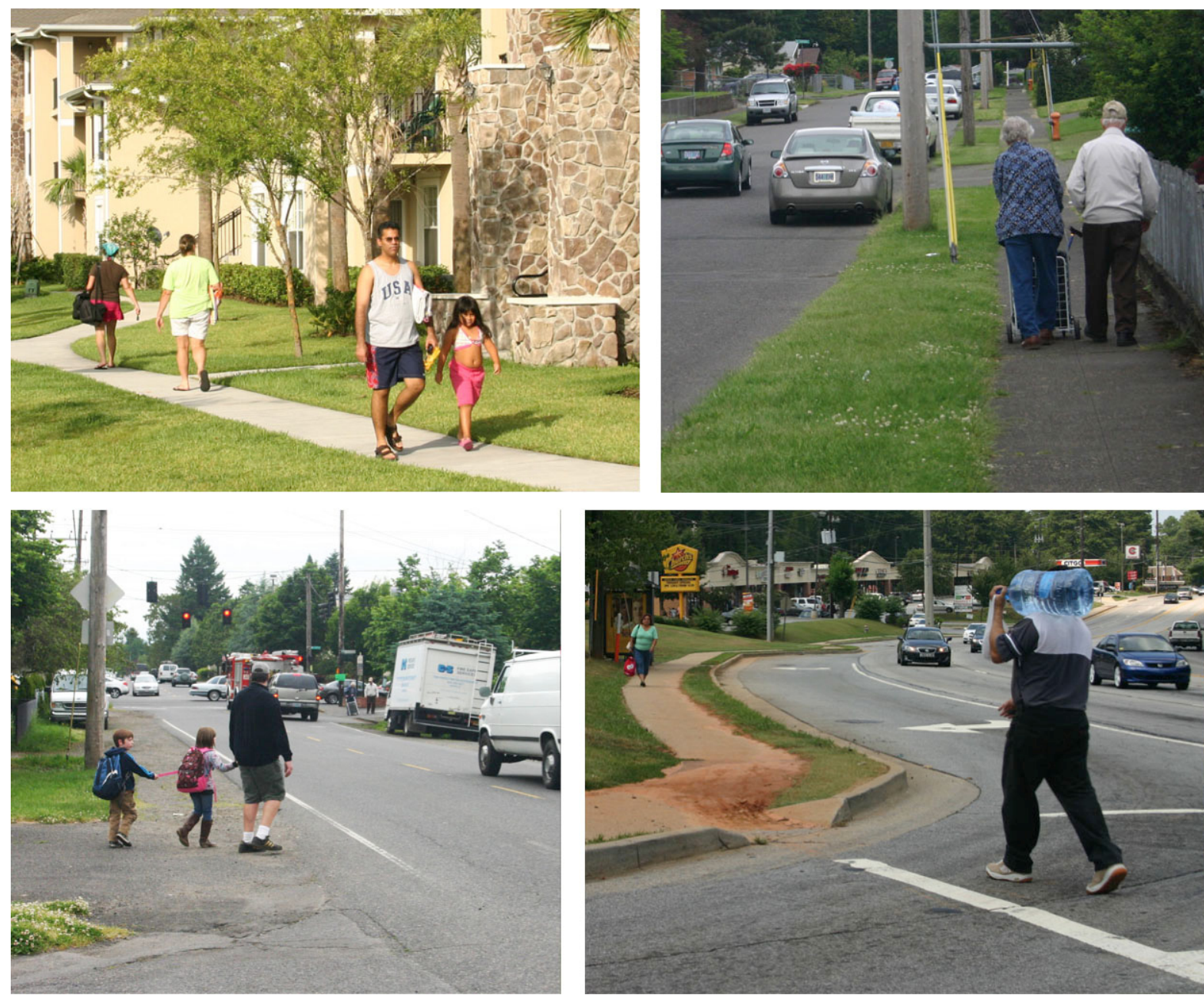

Figure 6: Pedestrians in Suburbia: Although often overlooked, walking in suburbia - especially around suburban commercial strips - is widespread.

\subsection{ROUTE EFFECTS: DISTANCE AND ARTERIALS}

Through the use of the survey's mapping section, 192 residents self-identified where they lived and were therefore included in an analysis of the distance of routes and qualities of routes between their home and the local commercial area. Figure 7 shows a histogram depicting the distances of routes from residents' homes to the LCA and whether they ever walked or not. At a broad scale, as expected, the further a resident lived from the LCA, the less likely they were to ever walk to it. What is interesting, however, is that the median route distance to the LCA for residents who walked was 1,793 feet. This is just over one-third of a mile, well above the widely accepted quarter mile typically used as the limits of walking distance. In fact, $66.3 \%$ of residents who reported walking to their LCA actually lived more than quarter mile from that LCA. 


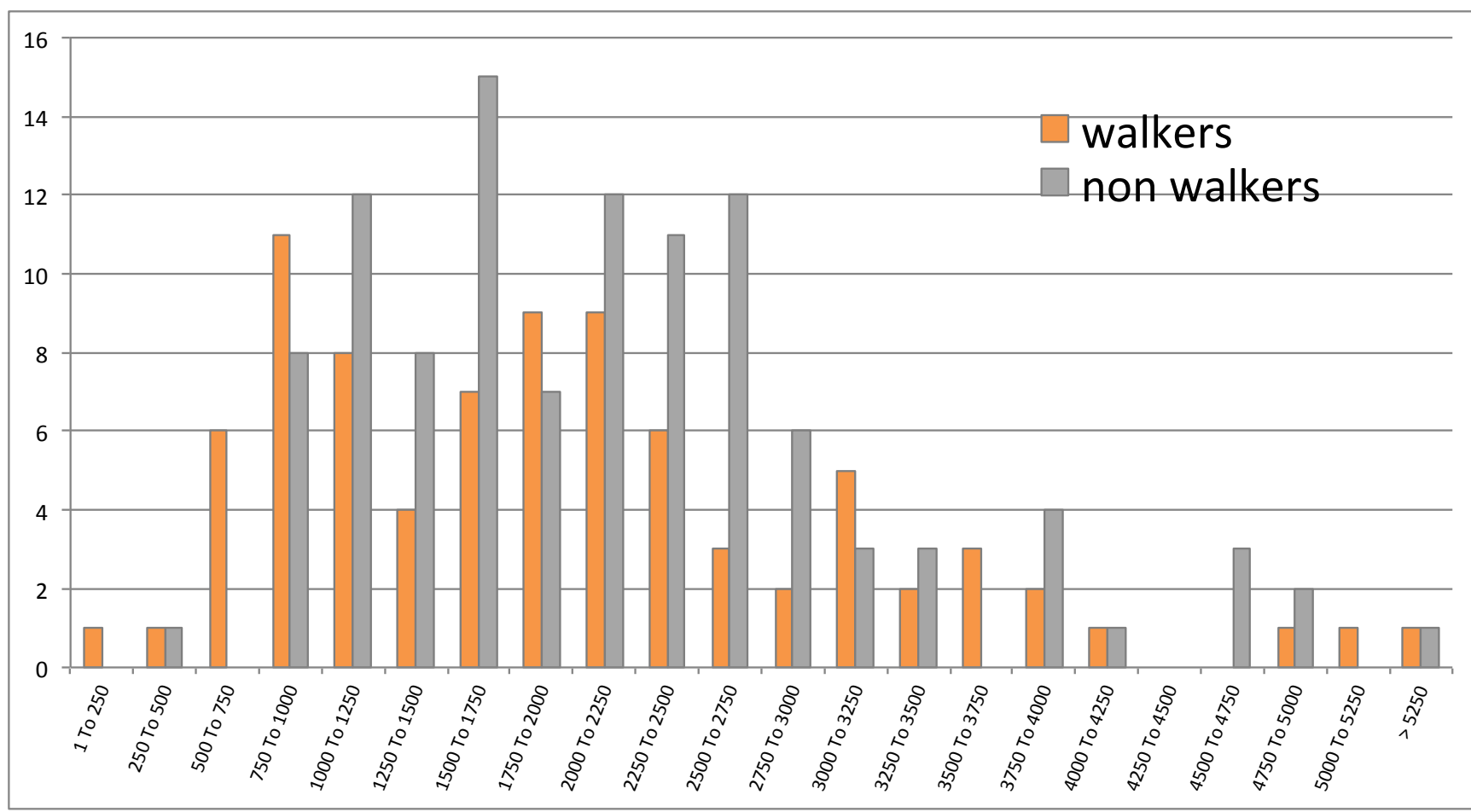

Figure 7: Histogram of Distance of Route From Residents' Homes to the Commercial Strip.

Using the pedestrian networks we had constructed previously, we were also able to analyze the quality of the routes from residents' homes to the LCA in terms of whether residents ever had to cross an arterial or walk along it. Table 5 shows the result of this analysis. In general, the introduction of arterial crossing or having to walk along arterials reduced the percentage of residents who reported walking to their LCA.

Table 5: Route Interaction with Arterials and Resident Mode Choice

\begin{tabular}{l|c|c}
\hline Residents whose routes included: & $\begin{array}{c}\text { \% Reporting } \\
\text { Walking }\end{array}$ & $\mathbf{n =}$ \\
\hline Crossing an arterial & $37 \%$ & 79 \\
\hline Not crossing an arterial & $48 \%$ & 113 \\
\hline & & \\
\hline Walking along an arterial & $41 \%$ & 117 \\
\hline Not walking along an arterial & $47 \%$ & 75 \\
\hline & & \\
\hline Both walking along and crossing an arterial & $37 \%$ & 79 \\
\hline Neither walking along nor crossing an arterial & $47 \%$ & 75 \\
\hline
\end{tabular}

A few issues are important to note with these results. First, as argued by others (Agrawal, Schlossberg et al., 2008), the quarter-mile walking distance metric that seems to be planners' and 
urban designers' stalwart mantra should be revisited and potentially revised upward. If further studies confirm that residents in suburbia actually walk farther distances, this modification would have significant impacts on how planners and designers lay out new developments and potentially locate centers and transit stops.

Second, if distance is a significant determinant of mode choice, then the connectivity of an area will have a direct effect on the degree of resident walking. More connected areas will, by definition, have more direct routes that will reduce travel distances. As mentioned previously, the original intention of this study was to specifically measure the rates of walking and biking in less-connected versus well-connected sites. The unexpected finding of a significant amount of informal networks and the effects of these networks on drastically increasing connectivity deterred this goal, but it is an area for further study.

Finally, the results show an effect on resident walking based on whether they had to walk along or across an arterial. Arterials are a fact of life in suburbia and their locations, once set, are not likely to change. Given that most suburban commercial strips are located along arterials, this means that half of the land area, if not the number of residents, will always be one arterial crossing away. Our study did not specifically look at design issues of these crossings (how they are marked, the timing of the lights, whether there are areas of refuge for pedestrians, etc.), but these factors may affect pedestrian comfort and hence affect mode choice. This is also an area for further study.

In regards to residents travelling along the arterial, there are two ways of addressing this issue: one is to make the path more pedestrian friendly, and the second is to minimize or eliminate it completely. In terms of the path itself, the design of the path along the arterial (whether it is buffered from the street, how it's buffered, the quality of sidewalk, etc.) might be affecting resident mode choice. This is a design question that needs further study to better understand what elements are most salient for residents. Depending on the situation, changes to the design of these areas may not be difficult to implement.

It is also possible, however, to reduce or completely eliminate paths along the arterials. Suburban street patterns that lack internal connectivity and instead are dendritic in nature force residents to travel along the arterial. In contrast, increasing internal connectivity - especially between different housing developments - reduces the need to travel along the arterial and instead allows residents to travel parallel to it along more pedestrian friendly streets. In effect, many of the informal networks identified in our site audits do just that and may be pointing not only to a desire by residents to reduce travel distance, but also to avoid less pedestrian-friendly streets. This is also an area for further study.

\subsection{TRANSIT USE}

While suburban areas are not typically as well served by transit as more urban areas, the transit that does exist often travels along arterials and has stops at larger neighborhood commercial centers. In addition to the commercial center, the transit lines themselves can act as pedestrian magnets. To understand the transit use of residents living near commercial centers, the survey asked residents if they used the transit stops located in their local LCA. The results of that question are shown in Table 6. 
Table 6: Household Use of Bus Stops

\begin{tabular}{|c|c|c|c|c|c|c|c|}
\hline & \multirow[b]{2}{*}{ OVERALL } & \multicolumn{4}{|c|}{ Portland } & \multicolumn{2}{|c|}{ Atlanta } \\
\hline & & $\begin{array}{c}\text { Oswego } \\
\text { Town } \\
\text { Center } \\
\end{array}$ & $\begin{array}{c}\text { Greenway } \\
\text { Town } \\
\text { Center } \\
\end{array}$ & $\begin{array}{l}\text { Meadow- } \\
\text { land }\end{array}$ & $\begin{array}{c}\text { San } \\
\text { Rafael }\end{array}$ & $\begin{array}{c}\text { Plantation } \\
\text { Pointe }\end{array}$ & $\begin{array}{c}\text { Candler- } \\
\text { McAfee }\end{array}$ \\
\hline Yes & $20 \%$ & $12 \%$ & $19 \%$ & $17 \%$ & $23 \%$ & $14 \%$ & $50 \%$ \\
\hline No & $78 \%$ & $87 \%$ & $78 \%$ & $80 \%$ & $75 \%$ & $84 \%$ & $46 \%$ \\
\hline Not Sure & $2 \%$ & $2 \%$ & $3 \%$ & $3 \%$ & $2 \%$ & $2 \%$ & $4 \%$ \\
\hline & 250 & 61 & 36 & 30 & 48 & 49 & 25 \\
\hline
\end{tabular}

Overall, one in five households $(20 \%)$ have at least one person in the household who uses transit. Although the sample sizes are too small for more detailed analysis, not surprisingly the responses suggest that income does have a correlation with transit use. The largest transit use was within the most economically challenged of the sites (Candler-McAfee $-50 \%$ ) while the most affluent areas (Oswego and Plantation Pointe) had the lowest percentage of households utilizing transit (12\% and $14 \%$, respectively). It is important to note that this analysis only looks at transit use originating from the households we surveyed and does not document individuals who are using the LCA itself as a destination. This is an area for further study.

Table 7: Household Transportation Mode to Bus Stops

\begin{tabular}{|c|c|c|c|c|c|c|c|}
\hline & \multirow[b]{2}{*}{ OVERALL } & \multicolumn{4}{|c|}{ Portland } & \multicolumn{2}{|c|}{ Atlanta } \\
\hline & & $\begin{array}{c}\text { Oswego } \\
\text { Town } \\
\text { Center } \\
\end{array}$ & $\begin{array}{c}\text { Greenway } \\
\text { Town } \\
\text { Center } \\
\end{array}$ & $\begin{array}{c}\text { Meadow- } \\
\text { land }\end{array}$ & $\begin{array}{c}\text { San } \\
\text { Rafael } \\
\text { Shopping } \\
\text { Center } \\
\end{array}$ & $\begin{array}{c}\text { Plantation } \\
\text { Pointe }\end{array}$ & $\begin{array}{c}\text { Candler- } \\
\text { McAfee }\end{array}$ \\
\hline Walk & $63 \%$ & $80 \%$ & $86 \%$ & $80 \%$ & $72 \%$ & $36 \%$ & $45 \%$ \\
\hline Bike & $3 \%$ & $10 \%$ & $0 \%$ & $10 \%$ & $0 \%$ & $9 \%$ & $0 \%$ \\
\hline Drive and Park & $14 \%$ & $10 \%$ & $7 \%$ & $0 \%$ & $11 \%$ & $18 \%$ & $21 \%$ \\
\hline Dropped Off & $14 \%$ & $0 \%$ & $7 \%$ & $0 \%$ & $17 \%$ & $18 \%$ & $28 \%$ \\
\hline Other & $5 \%$ & $0 \%$ & $0 \%$ & $10 \%$ & $0 \%$ & $18 \%$ & $7 \%$ \\
\hline
\end{tabular}

We asked residents using transit at the LCA how they travelled to the transit stop from their home (Table 7). A large majority of residents walk to the stop (63\%), while more than a quarter utilize a car for this trip by either driving themselves (14\%) or by getting dropped off at the transit stop (14\%). None of the case study sites have allocated transit parking, raising the question of whether some transit users are parking in the commercial center lots. Although the sample sizes are small, the responses suggest that a larger proportion of residents in Atlanta use the car for this type of trip. This might be due to the higher overall rate of driving in Atlanta giving residents more of an opportunity to be dropped off by another person in the household using the car.

To understand how transit use is interacting with the patronage of the commercial center, we asked residents how often their transit trips included shopping at the LCA. The response rates for the individual sites were low ( $\mathrm{n}=$ between 10-18), but aggregated, the responses show that $41 \%$ of residents using the bus stops are shopping at the LCA as part of their transit trip either sometimes or frequently. 
This data shows that transit use plays a significant role in residents' use and travel to their local commercial strip. It also shows that they overwhelmingly use active modes to get to the transit stops and would therefore be affected by the connectivity and quality of their routes to the LCA.

\subsection{WHY WALK? - MOTIVATIONS FOR MODE CHOICE}

As part of this study, we were interested in understanding the factors that help shape residents' decision to drive versus bike or walk and how these factors might relate to the built environment. To answer this question, we asked residents to rate two lists of factors in terms of how critical they were to their mode-choice decision. The first list was answered by residents who "ever drove" to the LCA, and was focused on factors that pulled residents towards driving or pushed them away from walking or biking. The second list was answered by residents who "ever walked or biked" to the LCA, and was focused on factors that pulled residents towards walking and biking or pushed them away from driving. The answers to these questions are summarized in tables 8 and 9 below.

\subsubsection{Motivations for Driving}

From the question answered by residents who "ever drove," convenience seems to be the largest pull towards driving. Trip chaining, the ease of carrying goods, the protection against weather afforded by a car, and the speed of car trips were consistently cited as critical to most residents in their decision to drive.

Interestingly, just over half of the respondents said they drove everywhere and did not even consider walking or biking, regardless if it actually was a possibility for the trips they were taking. This points to the culture of driving that is prevalent in suburbia and is a large barrier to expanding active travel in these areas.

Table 8: Percent of Households Reporting Factors as Somewhat Important or Critical to Their Decisions to Drive to the LCA

\begin{tabular}{|c|c|c|c|c|c|c|c|c|c|c|c|c|c|c|}
\hline \multirow{3}{*}{$\begin{array}{l}\text { S.I. = Somewhat Important } \\
\text { Crit. = Critical to Decision }\end{array}$} & \multirow{2}{*}{\multicolumn{2}{|c|}{ OVERALL }} & \multicolumn{8}{|c|}{ Portland } & \multicolumn{4}{|c|}{ Atlanta } \\
\hline & & & \multicolumn{2}{|c|}{$\begin{array}{l}\text { Oswego } \\
\text { Town } \\
\text { Center }\end{array}$} & \multicolumn{2}{|c|}{$\begin{array}{c}\text { Greenway } \\
\text { Town } \\
\text { Center }\end{array}$} & \multicolumn{2}{|c|}{$\begin{array}{l}\text { Meadow- } \\
\text { land }\end{array}$} & \multicolumn{2}{|c|}{$\begin{array}{l}\text { San Rafael } \\
\text { Shopping } \\
\text { Center }\end{array}$} & \multicolumn{2}{|c|}{$\begin{array}{l}\text { Plantation } \\
\text { Pointe }\end{array}$} & \multicolumn{2}{|c|}{$\begin{array}{l}\text { Candler- } \\
\text { McAfee }\end{array}$} \\
\hline & S.I. & Crit. & S.I. & Crit. & S.I. & Crit. & S.I. & Crit. & S.I. & Crit. & S.I. & Crit. & S.I. & Crit. \\
\hline $\begin{array}{l}\text { I often combine trips to my } \\
\text { shopping center with other trips } \\
\text { that require a car. }\end{array}$ & $33 \%$ & $57 \%$ & $46 \%$ & $46 \%$ & $29 \%$ & $62 \%$ & $36 \%$ & $52 \%$ & $24 \%$ & $69 \%$ & $21 \%$ & $66 \%$ & $42 \%$ & $46 \%$ \\
\hline $\begin{array}{l}\text { There is too much for me to carry, } \\
\text { so I can't walk or bike. }\end{array}$ & $34 \%$ & $52 \%$ & $49 \%$ & $38 \%$ & $29 \%$ & $62 \%$ & $40 \%$ & $48 \%$ & $11 \%$ & $71 \%$ & $35 \%$ & $52 \%$ & $42 \%$ & $38 \%$ \\
\hline $\begin{array}{l}\text { I do not like to walk or bike in } \\
\text { bad weather. }\end{array}$ & $33 \%$ & $46 \%$ & $31 \%$ & $44 \%$ & $38 \%$ & $41 \%$ & $32 \%$ & $36 \%$ & $42 \%$ & $49 \%$ & $29 \%$ & $52 \%$ & $25 \%$ & $54 \%$ \\
\hline $\begin{array}{l}\text { I don't have enough time to walk } \\
\text { or bike. }\end{array}$ & $39 \%$ & $25 \%$ & $38 \%$ & $30 \%$ & $32 \%$ & $27 \%$ & $30 \%$ & $22 \%$ & $40 \%$ & $20 \%$ & $45 \%$ & $26 \%$ & $50 \%$ & $17 \%$ \\
\hline
\end{tabular}




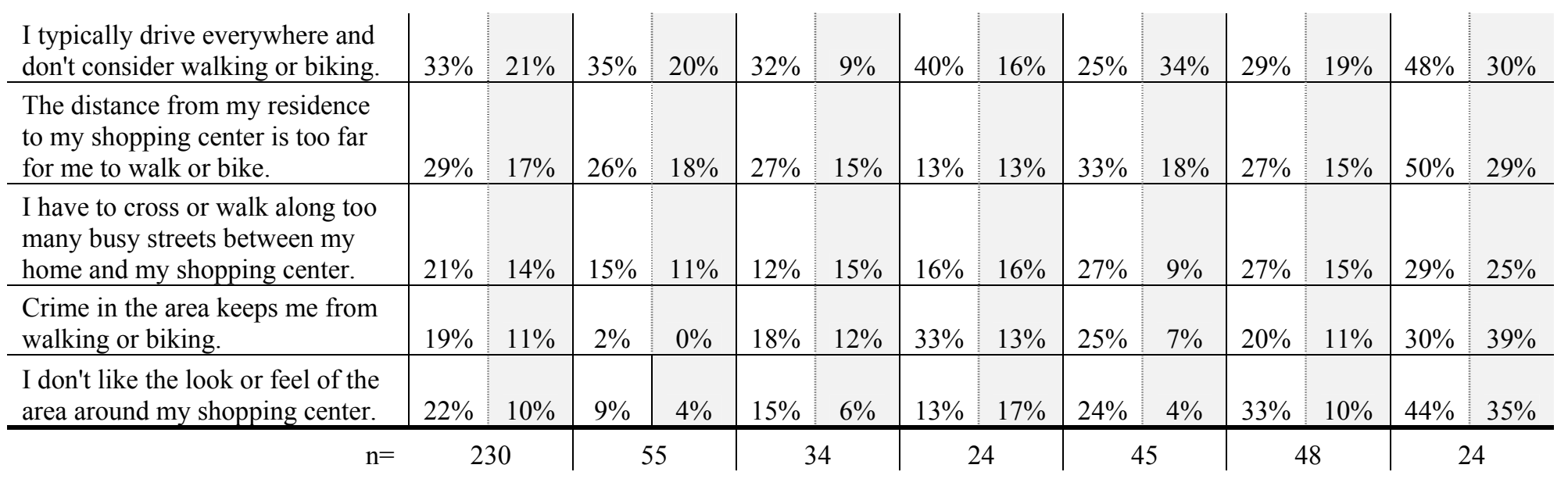

Factors related directly to the built environment, such as the distance to the LCA from the resident's home, the look and feel of the LCA, and the need to walk along or across busy streets, all ranked low overall compared to the criteria related to convenience. That said, a large number of residents still reported considering these factors in their mode-choice decision. Nearly half of respondents (46\%) reported the distance between their home and the LCA as a somewhat important or critical factor, and over a third (35\%) said the same about walking along or across busy streets. The distance factor is interesting in that all of the residents surveyed lived - as the crow flies - within what is typically considered to be walking distance to the LCA and many lived within in-network walking distance to the LCA. It is the connectivity or lack of connectivity in the pedestrian network between residents' homes and the LCA that extended this distance and may be factoring into this constraint. This was especially true for Candler-McAfee, where nearly $80 \%$ of respondents reported the distance to the LCA as a problem.

The prevalence of crime was reported as an incentive to drive for just under a third of respondents, although this was substantially higher for the lower-income sites of CandlerMcAfee, Meadowlands and San Rafael.

\subsubsection{Motivations for Walking and Biking}

In this series of questions we looked at the factors that pull residents towards walking and biking and push them away from driving. Answers to these questions show that residents who do walk or bike tend to agree that the health and enjoyment of walking is critical to their decision (good for health, enjoy being outside, good for the environment). Although different sites varied in terms of the degree to which these issues were either somewhat important or critical, there was a surprising amount of uniformity in the combined percentage of residents who reported these factors as important or critical.

Table 9: Percent of Households Reporting Factors as Somewhat Important or Critical to Their Decisions to Walk or Bike to the LCA

\begin{tabular}{|c|c|c|c|c|c|c|}
\hline \multirow[b]{2}{*}{ OVERALL } & \multicolumn{4}{|c|}{ Portland } & \multicolumn{2}{|c|}{ Atlanta } \\
\hline & $\begin{array}{l}\text { Oswego } \\
\text { Town } \\
\text { Center }\end{array}$ & $\begin{array}{c}\text { Greenway } \\
\text { Town } \\
\text { Center }\end{array}$ & $\begin{array}{l}\text { Meadow- } \\
\text { land }\end{array}$ & $\begin{array}{c}\text { San Rafael } \\
\text { Shopping } \\
\text { Center }\end{array}$ & $\begin{array}{c}\text { Plantation } \\
\text { Pointe }\end{array}$ & $\begin{array}{c}\text { Candler- } \\
\text { McAfee }\end{array}$ \\
\hline
\end{tabular}




\begin{tabular}{|c|c|c|c|c|c|c|c|c|c|c|c|c|c|c|}
\hline $\begin{array}{l}\text { S.I. }=\text { Somewhat Important } \\
\text { Crit. = Critical to Decision }\end{array}$ & S.I. & Crit. & S.I. & Crit. & S.I. & Crit. & S.I. & Crit. & S.I. & Crit. & S.I. & Crit. & S.I. & Crit. \\
\hline $\begin{array}{l}\text { I believe walking or biking is } \\
\text { good for my health. }\end{array}$ & $47 \%$ & $49 \%$ & $40 \%$ & $60 \%$ & $42 \%$ & $58 \%$ & $46 \%$ & $46 \%$ & $62 \%$ & $31 \%$ & $40 \%$ & $60 \%$ & $60 \%$ & $27 \%$ \\
\hline I enjoy being outside. & $47 \%$ & $47 \%$ & $33 \%$ & $64 \%$ & $54 \%$ & $46 \%$ & $54 \%$ & $39 \%$ & $6 \%$ & $46 \%$ & $3 \%$ & $2 \%$ & $87 \%$ & $0 \%$ \\
\hline $\begin{array}{l}\text { I believe walking or biking is } \\
\text { good for the environment. }\end{array}$ & $47 \%$ & $41 \%$ & $53 \%$ & $44 \%$ & $33 \%$ & $46 \%$ & $50 \%$ & $42 \%$ & $42 \%$ & $42 \%$ & $38 \%$ & $52 \%$ & $71 \%$ & $7 \%$ \\
\hline I want to save money. & $49 \%$ & $17 \%$ & $41 \%$ & $9 \%$ & $50 \%$ & $21 \%$ & $42 \%$ & $25 \%$ & $65 \%$ & $12 \%$ & $40 \%$ & $30 \%$ & $57 \%$ & $14 \%$ \\
\hline $\begin{array}{l}\text { I enjoy seeing or meeting other } \\
\text { people while I walk or bike. }\end{array}$ & $38 \%$ & $14 \%$ & $46 \%$ & $27 \%$ & $46 \%$ & $4 \%$ & $31 \%$ & $16 \%$ & $23 \%$ & $12 \%$ & $38 \%$ & $14 \%$ & $43 \%$ & $7 \%$ \\
\hline $\begin{array}{l}\text { It is faster or easier to walk or } \\
\text { bike than to drive to my } \\
\text { shopping center. }\end{array}$ & $35 \%$ & $13 \%$ & $27 \%$ & $12 \%$ & $42 \%$ & $8 \%$ & $8 \%$ & $25 \%$ & $46 \%$ & $4 \%$ & $0 \%$ & $0 \%$ & $75 \%$ & $0 \%$ \\
\hline I do not have access to a car. & $8 \%$ & $10 \%$ & $0 \%$ & $3 \%$ & $9 \%$ & $4 \%$ & $8 \%$ & $0 \%$ & $12 \%$ & $12 \%$ & $5 \%$ & $15 \%$ & $27 \%$ & $36 \%$ \\
\hline $\begin{array}{l}\text { Parking at my shopping center is } \\
\text { difficult. }\end{array}$ & $30 \%$ & $5 \%$ & $52 \%$ & $6 \%$ & $13 \%$ & $0 \%$ & $8 \%$ & $0 \%$ & $27 \%$ & $0 \%$ & $35 \%$ & $15 \%$ & $21 \%$ & $7 \%$ \\
\hline $\mathrm{n}=$ & & & & & & & & & & 0 & & & & 8 \\
\hline
\end{tabular}

Interestingly, the cost of driving is definitely a push against it. Sixty-six percent of respondents cited this as somewhat important or critical to their decision to walk or bike. This was surprisingly consistent regardless of case study site. Saving money was reported as somewhat important or critical for at least half of the residents in any site, with some areas reporting this as an important or critical factor for up to three-quarters of residents who walked or biked.

Walking for issues of convenience (faster to do so than driving) was important or critical for nearly $50 \%$ of residents. Although lower on the list than other factors, the point that this factor was salient for such a large proportion of residents suggests that - as others have found increasing the convenience of walking and biking in relation to driving is a critical aspect to increasing active travel. The final factor related to the ease of parking in the shopping center reinforces this point, with approximately a third of residents incorporating this issue into their decision to walk or bike.

\subsubsection{Convenience, Cost and Culture: Motivations for Mode Choice}

The data reported above suggests that the motivations for mode choice in suburbia can be categorized as relating to issues of convenience, cost and culture. All three of these areas hold potential for mode shifts from driving to walking and biking, but chart substantially different courses for implementation.

Not unlike previous research on mode choice, convenience ranks highly among the motivations for choosing one mode over another. As decisions are made on the relative convenience between competing modes, it is both the ease of one mode and the difficulty of another that must be taken into account. The survey data suggest that resident mode choice for trips to the local commercial area are often made based on the convenience of chaining trips. This is both for 
residents who are stopping at their local commercial area on their way to or from another auto trip or to or from a transit trip. If the auto-dominated nature of suburban travel continues, these short, potential active transport trips will continue to be made by car. Similarly, simply based on convenience, as transit ridership increases so will the active travel to the LCA.

Some conveniences of the automobile will continue to pull mode share towards auto use. The ease of carrying goods in a car and the difficulty of walking and biking in inclement weather favor the use of the automobile and may be difficult to overcome. Conversely, many residents see auto trips to the LCA as actually being more difficult than walking or biking. One of the factors this study has revealed that might be affecting this could be the circuitous nature of the street network as opposed to the pedestrian network. Pedestrian networks, especially with the addition of informal networks, provide fairly direct access to commercial areas while street networks can be much less direct and often include traffic lights, turning into or out of fastmoving traffic, and the time it takes to park the car.

Cost is a second factor affecting residents' mode choice to their LCA. During the weeks when this survey was administered, gasoline prices were approximately $\$ 3.60$ per gallon (U.S. Energy Information Administration, 2012). This was during a period of rapid increase in the cost of fuel and at the writing of this report, fuel continues to cost a similar amount and may continue to rise. The survey responses show that residents are tracking the cost of driving and tend to see walking as a more affordable alternative. If the cost of fuel continues to increase, this data suggests it will have an effect on walking and biking rates in suburbia. Even if longer work-related trips continue to be dominated by car travel, these shorter utilitarian trips to the LCA could shift to the more affordable active travel modes.

Finally, what we might call the "culture of travel" in these suburban areas is also affecting mode choice. More than half of the respondents who drove reported that they don't consider walking or biking as an alternative as they see their car as the default mode for all travel. This is specifically for trips to the LCA that are within walking and biking distance of their residences. If the "culture of travel" is completely auto-dominated without even the consideration of other modes, there is little that can shift mode choice, as arguably no choice is being made.

Conversely, a "culture of travel" that includes walking and biking as a legitimate and beneficial mode choice seems to increase that activity. Nearly all respondents who walked or biked were motivated by reasons of health, enjoyment and concern for the environment. This suggests that social campaigns or public health campaigns might play a significant role in increasing active travel - even in suburbia. This is a topic for further study.

The results of this survey suggest that all three motivations - convenience, cost and culture should be addressed to increase active travel-mode share.

\subsection{INCREASING ACTIVE TRAVEL?}

The survey asked residents if they would walk or bike to their LCA more frequently if it were made more convenient to do so (Table 10). Approximately a third said this would affect their mode choice, a third said it would not, and a third said it was already convenient and, therefore, would not affect their choice. Those who answered that increased ease or convenience would 
increase their rate of walking and biking were then asked to rate the degree to which a series of physical design factors would affect their mode choice (Table 11).

Table 10: Would Residents Walk or Bike if it were Made Easier or More Convenient?

\begin{tabular}{|c|c|c|c|c|c|c|c|}
\hline & \multirow[b]{2}{*}{ OVERALL } & \multicolumn{4}{|c|}{ Portland } & \multicolumn{2}{|c|}{ Atlanta } \\
\hline & & $\begin{array}{c}\text { Oswego } \\
\text { Town } \\
\text { Center }\end{array}$ & $\begin{array}{c}\text { Greenway } \\
\text { Town } \\
\text { Center }\end{array}$ & $\begin{array}{c}\text { Meadow- } \\
\text { land }\end{array}$ & $\begin{array}{c}\text { San } \\
\text { Rafael } \\
\text { Shopping } \\
\text { Center }\end{array}$ & $\begin{array}{c}\text { Plantation } \\
\text { Pointe }\end{array}$ & $\begin{array}{c}\text { Candler- } \\
\text { McAfee }\end{array}$ \\
\hline Yes & $34 \%$ & $29 \%$ & $29 \%$ & $28 \%$ & $31 \%$ & $47 \%$ & $46 \%$ \\
\hline No & $27 \%$ & $34 \%$ & $23 \%$ & $45 \%$ & $29 \%$ & $24 \%$ & $27 \%$ \\
\hline $\begin{array}{l}\text { No - Already } \\
\text { convenient }\end{array}$ & $39 \%$ & $37 \%$ & $49 \%$ & $28 \%$ & $40 \%$ & $29 \%$ & $27 \%$ \\
\hline & 109 & 59 & 35 & 29 & 48 & 49 & 26 \\
\hline
\end{tabular}

Of those answering this question, half said "Providing more or better places to walk" would be critical to their decision, and an additional quarter said this would be somewhat important. While this question did not differentiate between issues of missing sidewalks, inadequate sidewalks, informal connections, or the quality of the areas surrounding the sidewalks (trees, buffers, furniture), it does suggest that the quality and extent of the pedestrian network and the built environment is, as a whole, considered a critical issue in the decision to walk or bike.

The next two most important issues both related to automobiles, either separating them from the pedestrian paths or simply reducing their number or speed. The lowest-rated three factors all related to the route from residents' homes to the LCA. This included the look and feel of the route, the distance and directness of the route, and obstacles within the route. Even though these factors had the lowest level of agreement across residents, still approximately half of the respondents considered each of these factors as somewhat important or critical to increasing walking and biking. In addition, previous analysis of actual travel behavior (in this study and others) shows an increase in active travel when distances are reduced.

Table 11: Importance of Potential Improvements in Residents' Decision to Walk or Bike

\begin{tabular}{l|c|c}
\hline \multirow{2}{*}{} & \multicolumn{2}{|c}{ OVERALL } \\
\cline { 2 - 3 } & $\begin{array}{c}\text { Somewhat } \\
\text { Important }\end{array}$ & $\begin{array}{c}\text { Critical to my } \\
\text { Decision }\end{array}$ \\
\hline Providing more or better places to walk. & $25 \%$ & $50 \%$ \\
\hline Separating the pedestrian path from vehicle traffic. & $41 \%$ & $34 \%$ \\
\hline Reducing the number or speed of cars. & $44 \%$ & $24 \%$ \\
\hline $\begin{array}{l}\text { Improving the look and feel of the area between my } \\
\text { residence and the center. }\end{array}$ & $36 \%$ & $23 \%$ \\
\hline $\begin{array}{l}\text { Reducing the distance of the trip by making a more } \\
\text { direct path between my house and the center. }\end{array}$ & $33 \%$ & $17 \%$ \\
\hline $\begin{array}{l}\text { Reducing obstacles (such as fences) between my } \\
\text { residence and the shopping center. }\end{array}$ & $38 \%$ & $9 \%$ \\
\hline
\end{tabular}

$\mathrm{n}=119$ 
Another gauge of the importance residents give to easy walking access to stores and restaurants can be seen by how critical this factor is in their decision of where to live. In responses to this question (Table 12), half of the respondents said this was either somewhat important or critical to their decision in finding a home. As an indicator of the relative importance of this, ease of walking to stores and restaurants was critical to more residents than ease of walking to neighborhood schools - a hallmark of suburban living. Only ease of walking access to open space and parks ranked higher. Interestingly, $43 \%$ of respondents ranked ease of walking access to public transportation as somewhat important or critical to their decision of where to live. This number was substantially higher in the lower-income area of Candler-McAfee (75\%), but was still one-third of respondents (34\%) in the much higher-income Oswego Town Center.

Table 12: Percent of Residents Reporting Ease of Walking to Destination as Somewhat Important or Critical to Their Decisions to Choose their Current Residence

\begin{tabular}{l|c|c|c|c|c|c|c}
\hline & & \multicolumn{2}{c|}{ Portland } & \multicolumn{2}{c}{ Atlanta } \\
\cline { 2 - 8 } & OVERALL & $\begin{array}{c}\text { Oswego } \\
\text { Town } \\
\text { Center }\end{array}$ & $\begin{array}{c}\text { Greenway } \\
\text { Town } \\
\text { Center }\end{array}$ & $\begin{array}{c}\text { Meadow- } \\
\text { land }\end{array}$ & $\begin{array}{c}\text { Safael } \\
\text { Shopping } \\
\text { Center }\end{array}$ & $\begin{array}{c}\text { Plantation } \\
\text { Pointe }\end{array}$ & $\begin{array}{c}\text { Candler- } \\
\text { McAfee }\end{array}$ \\
\hline $\begin{array}{l}\text { To Stores or } \\
\text { Restaurants }\end{array}$ & $50 \%$ & $50 \%$ & $61 \%$ & $33 \%$ & $50 \%$ & $40 \%$ & $79 \%$ \\
\hline $\begin{array}{l}\text { To } \\
\begin{array}{l}\text { Neighborhood } \\
\text { Schools }\end{array}\end{array}$ & $41 \%$ & $31 \%$ & $36 \%$ & $36 \%$ & $58 \%$ & $24 \%$ & $71 \%$ \\
\hline $\begin{array}{l}\text { To Public } \\
\text { Transportation }\end{array}$ & $43 \%$ & $34 \%$ & $50 \%$ & $35 \%$ & $48 \%$ & $29 \%$ & $75 \%$ \\
\hline $\begin{array}{l}\text { To Open Space } \\
\text { or Parks }\end{array}$ & $61 \%$ & $56 \%$ & $81 \%$ & $50 \%$ & $59 \%$ & $54 \%$ & $75 \%$ \\
\hline \multicolumn{1}{c}{$\mathrm{n}=$} & 236 & 57 & 36 & 26 & 46 & 46 & 24
\end{tabular}

\subsection{DEMOGRAPHIC INFORMATION}

Tables 13 and 14 show the demographic information and selected demographic comparisons of Census data for residents living within one mile of the study's commercial sites. Having relative parity between the respondents' demographics and those of the residents of the area as a whole gives a sense of the representativeness of the sample. For the Census data, we used CoStar's demographic data. This data is derived through an algorithm that takes proportional amounts of Census block-group data and assigned this amount to the one-mile radius of the subject sites. For this reason, this data is an approximation of demographics within the one-mile radius.

The sites as a whole cover a wide range of demographic conditions in terms of race and income. As expected, the Portland sites tend to be predominantly Caucasian, while the Atlanta sites have a greater proportion of African-American residents. In terms of income, Oswego Town Center, Greenaway Town Center and Plantation Pointe are the more affluent communities, with Oswego being the most affluent. Meadowland, San Rafael Shopping Center and Candler-McAfee are more economically challenged, with Candler-McAfee being an extreme of that condition compared to the other two sites. 
While the course grain typology of the suburban commercial strip, single-use land use and surrounding single-family and multifamily housing is consistent and typical, the demographics vary. The one consistent trend across all sites (that might be considered a trend of suburbia in general) is that residents of the study sites tend to be middle-aged and older with relatively few householders under 25 years of age.

Table 13: Demographics of Survey Respondents

\begin{tabular}{|c|c|c|c|c|c|c|c|}
\hline & \multirow[b]{2}{*}{ OVERALL } & \multicolumn{4}{|c|}{ Portland } & \multicolumn{2}{|c|}{ Atlanta } \\
\hline & & $\begin{array}{c}\text { Oswego } \\
\text { Town } \\
\text { Center } \\
\end{array}$ & $\begin{array}{c}\text { Greenway } \\
\text { Town } \\
\text { Center } \\
\end{array}$ & $\begin{array}{l}\text { Meadow- } \\
\text { land }\end{array}$ & $\begin{array}{c}\text { San } \\
\text { Rafael } \\
\text { Shopping } \\
\text { Center } \\
\end{array}$ & $\begin{array}{c}\text { Plantation } \\
\text { Pointe }\end{array}$ & $\begin{array}{c}\text { Candler- } \\
\text { McAfee }\end{array}$ \\
\hline \multicolumn{8}{|l|}{ Age } \\
\hline Under 25 & $6 \%$ & $3 \%$ & $3 \%$ & $13 \%$ & $4 \%$ & $6 \%$ & $11 \%$ \\
\hline $25-34$ & $7 \%$ & $5 \%$ & $8 \%$ & $6 \%$ & $2 \%$ & $14 \%$ & $7 \%$ \\
\hline $35-44$ & $17 \%$ & $10 \%$ & $32 \%$ & $9 \%$ & $14 \%$ & $31 \%$ & $7 \%$ \\
\hline $45-54$ & $18 \%$ & $10 \%$ & $11 \%$ & $13 \%$ & $34 \%$ & $16 \%$ & $25 \%$ \\
\hline $55-64$ & $24 \%$ & $32 \%$ & $19 \%$ & $22 \%$ & $18 \%$ & $22 \%$ & $25 \%$ \\
\hline $65-74$ & $17 \%$ & $24 \%$ & $19 \%$ & $16 \%$ & $14 \%$ & $10 \%$ & $18 \%$ \\
\hline $75+$ & $11 \%$ & $16 \%$ & $8 \%$ & $22 \%$ & $14 \%$ & $0 \%$ & $7 \%$ \\
\hline
\end{tabular}

\begin{tabular}{|c|c|c|c|c|c|c|c|}
\hline \multicolumn{8}{|c|}{ Gender of Respondent } \\
\hline Male & $43 \%$ & $32 \%$ & $41 \%$ & $40 \%$ & $48 \%$ & $50 \%$ & $57 \%$ \\
\hline Female & $57 \%$ & $68 \%$ & $60 \%$ & $60 \%$ & $52 \%$ & $50 \%$ & $44 \%$ \\
\hline & $\mathrm{n}=244$ & $\mathrm{n}=60$ & $\mathrm{n}=37$ & $\mathrm{n}=30$ & $\mathrm{n}=48$ & $\mathrm{n}=46$ & $\mathrm{n}=23$ \\
\hline
\end{tabular}

\begin{tabular}{|c|c|c|c|c|c|c|c|}
\hline \multicolumn{8}{|l|}{$\begin{array}{l}\text { Households With } \\
\text { Children }\end{array}$} \\
\hline Younger than 6 & $10 \%$ & $0 \%$ & $16 \%$ & $6 \%$ & $8 \%$ & $20 \%$ & $14 \%$ \\
\hline Between 6-11 years & $10 \%$ & $8 \%$ & $24 \%$ & $6 \%$ & $8 \%$ & $6 \%$ & $7 \%$ \\
\hline Between $12-17$ years & $10 \%$ & $6 \%$ & $16 \%$ & $6 \%$ & $14 \%$ & $6 \%$ & $21 \%$ \\
\hline
\end{tabular}
$\mathrm{n}=181$

\begin{tabular}{|c|c|c|c|c|c|c|c|}
\hline \multicolumn{8}{|l|}{ Education } \\
\hline $\begin{array}{l}\text { Did not finish High } \\
\text { School }\end{array}$ & $5 \%$ & $5 \%$ & $3 \%$ & $4 \%$ & $2 \%$ & $2 \%$ & $18 \%$ \\
\hline High School & $27 \%$ & $12 \%$ & $19 \%$ & $39 \%$ & $43 \%$ & $17 \%$ & $46 \%$ \\
\hline $\begin{array}{l}\text { College or Associates } \\
\text { Degree }\end{array}$ & $49 \%$ & $53 \%$ & $50 \%$ & $43 \%$ & $46 \%$ & $62 \%$ & $23 \%$ \\
\hline Post-Graduate & $20 \%$ & $29 \%$ & $28 \%$ & $14 \%$ & $9 \%$ & $19 \%$ & $14 \%$ \\
\hline & $n=226$ & $\mathrm{n}=58$ & $n=32$ & $\mathrm{n}=28$ & $n=44$ & $n=42$ & $n=22$ \\
\hline
\end{tabular}


Table 14: Demographics of Survey Respondents and Census Comparison

\begin{tabular}{|c|c|c|c|c|c|c|c|c|c|c|c|c|c|}
\hline & \multirow{3}{*}{ OVERALL } & \multicolumn{8}{|c|}{ Portland } & \multicolumn{4}{|c|}{ Atlanta } \\
\hline & & \multicolumn{2}{|c|}{$\begin{array}{l}\text { Oswego Town } \\
\text { Center }\end{array}$} & \multicolumn{2}{|c|}{$\begin{array}{c}\text { Greenway Town } \\
\text { Center }\end{array}$} & \multicolumn{2}{|c|}{ Meadowland } & \multicolumn{2}{|c|}{$\begin{array}{c}\text { San Rafael } \\
\text { Shopping } \\
\text { Center }\end{array}$} & \multicolumn{2}{|c|}{$\begin{array}{l}\text { Plantation } \\
\text { Pointe }\end{array}$} & \multicolumn{2}{|c|}{$\begin{array}{l}\text { Candler- } \\
\text { McAfee }\end{array}$} \\
\hline & & $\begin{array}{l}\text { Survey } \\
\text { Resp. }\end{array}$ & Census & $\begin{array}{l}\text { Survey } \\
\text { Resp. }\end{array}$ & Census & $\begin{array}{l}\text { Survey } \\
\text { Resp. }\end{array}$ & Census & $\begin{array}{l}\text { Survey } \\
\text { Resp. }\end{array}$ & Census & $\begin{array}{l}\text { Survey } \\
\text { Resp. }\end{array}$ & Census & $\begin{array}{l}\text { Survey } \\
\text { Resp. }\end{array}$ & Census \\
\hline \multicolumn{14}{|l|}{ Household type } \\
\hline Single & $17 \%$ & $12 \%$ & $27 \%$ & $8 \%$ & $29 \%$ & $23 \%$ & $29 \%$ & $15 \%$ & $29 \%$ & $26 \%$ & $46 \%$ & $28 \%$ & $48 \%$ \\
\hline Divorced & $19 \%$ & $27 \%$ & $12 \%$ & $16 \%$ & $15 \%$ & $13 \%$ & $12 \%$ & $27 \%$ & $13 \%$ & $15 \%$ & $13 \%$ & $32 \%$ & $14 \%$ \\
\hline Widowed & $9 \%$ & $6 \%$ & $6 \%$ & $16 \%$ & $5 \%$ & $7 \%$ & $8 \%$ & $6 \%$ & $9 \%$ & $4 \%$ & $2 \%$ & $8 \%$ & $6 \%$ \\
\hline Married/Dom. Pr. & $55 \%$ & $52 \%$ & $56 \%$ & $60 \%$ & $52 \%$ & $57 \%$ & $51 \%$ & $52 \%$ & $49 \%$ & $55 \%$ & $38 \%$ & $32 \%$ & $32 \%$ \\
\hline & $\mathrm{n}=247$ & $\mathrm{n}=60$ & & $\mathrm{n}=37$ & & $\mathrm{n}=30$ & & $\mathrm{n}=48$ & & $\mathrm{n}=47$ & & $\mathrm{n}=25$ & \\
\hline \multicolumn{14}{|l|}{ Race } \\
\hline American Indian or Alaska Native & $4 \%$ & $7 \%$ & $0 \%$ & $3 \%$ & $1 \%$ & $6 \%$ & $1 \%$ & $2 \%$ & $1 \%$ & $0 \%$ & $0 \%$ & $4 \%$ & $0 \%$ \\
\hline $\begin{array}{l}\text { Native Hawaiian or Pacific } \\
\text { Islander }\end{array}$ & $2 \%$ & $0 \%$ & $0 \%$ & $6 \%$ & $1 \%$ & $3 \%$ & $0 \%$ & $0 \%$ & $0 \%$ & $0 \%$ & $0 \%$ & $4 \%$ & $0 \%$ \\
\hline Asian & $4 \%$ & $2 \%$ & $6 \%$ & $16 \%$ & $8 \%$ & $3 \%$ & $6 \%$ & $4 \%$ & $10 \%$ & $2 \%$ & $6 \%$ & $0 \%$ & $0 \%$ \\
\hline Black or African-American & $11 \%$ & $0 \%$ & $1 \%$ & $3 \%$ & $2 \%$ & $3 \%$ & $2 \%$ & $2 \%$ & $3 \%$ & $18 \%$ & $38 \%$ & $61 \%$ & $88 \%$ \\
\hline Latino/Hispanic & $7 \%$ & $7 \%$ & & $5 \%$ & & $9 \%$ & & $8 \%$ & & $6 \%$ & & $4 \%$ & \\
\hline White/Caucasian (Non-Hispanic) & $70 \%$ & $89 \%$ & $88 \%$ & $70 \%$ & $79 \%$ & $78 \%$ & $78 \%$ & $80 \%$ & $77 \%$ & $65 \%$ & $45 \%$ & $14 \%$ & $10 \%$ \\
\hline & $\mathrm{n}=258$ & $\mathrm{n}=62$ & & $\mathrm{n}=37$ & & $n=32$ & & $\mathrm{n}=50$ & & $\mathrm{n}=49$ & & $\mathrm{n}=28$ & \\
\hline \multicolumn{14}{|l|}{ Income } \\
\hline Less than $\$ 29,999$ & $25 \%$ & $10 \%$ & $16 \%$ & $29 \%$ & $20 \%$ & $39 \%$ & $21 \%$ & $26 \%$ & $24 \%$ & $15 \%$ & $21 \%$ & $54 \%$ & $44 \%$ \\
\hline$\$ 30,000-\$ 49,999$ & $23 \%$ & $14 \%$ & $16 \%$ & $10 \%$ & $19 \%$ & $30 \%$ & $24 \%$ & $37 \%$ & $20 \%$ & $22 \%$ & $25 \%$ & $23 \%$ & $24 \%$ \\
\hline$\$ 50,000-\$ 69,999$ & $19 \%$ & $22 \%$ & $14 \%$ & $10 \%$ & $17 \%$ & $22 \%$ & $19 \%$ & $23 \%$ & $21 \%$ & $20 \%$ & $22 \%$ & $9 \%$ & $12 \%$ \\
\hline$\$ 70,000-\$ 89,999$ & $11 \%$ & $14 \%$ & $11 \%$ & $23 \%$ & $14 \%$ & $0 \%$ & $14 \%$ & $5 \%$ & $16 \%$ & $15 \%$ & $14 \%$ & $5 \%$ & $8 \%$ \\
\hline$\$ 90,000$ or More & $23 \%$ & $39 \%$ & $43 \%$ & $29 \%$ & $30 \%$ & $9 \%$ & $22 \%$ & $9 \%$ & $19 \%$ & $29 \%$ & $19 \%$ & $9 \%$ & $11 \%$ \\
\hline & $\mathrm{n}=209$ & $n=49$ & & $\mathrm{n}=31$ & & $n=23$ & & $n=43$ & & $\mathrm{n}=41$ & & $\mathrm{n}=22$ & \\
\hline
\end{tabular}

Census Data has been processed by CoStar and here we are reporting their one-mile estimated demographic information.

Income data from Census is approximate as ranges were modified to match survey ranges.

Race data from Census does not total $100 \%$ as we are not listing the "Two or More Races" and "Other Race" categories. 


\subsection{CONCLUSION}

Walking and biking, while often considered to be antithetical to suburban development, is actually quite prevalent in areas around commercial strips. These areas typically have a strong mix of pedestrian magnets, often include mid- to high-density multifamily housing, and - from the findings in this study - are surprisingly well-connected. Much of this connectivity is due in part to informal pedestrian networks found throughout study sites. These networks suggest a pent-up demand and interest from residents in having direct pedestrian and bike paths between their homes and their local commercial area. At the same time, these informal connections are not equivalent to formalized connections, and we do not yet understand how issues of safety, path quality and liability are affecting the use and genesis of these paths. This is an area for further study.

Suburban commercial strips are widespread throughout this country and each one has a substantial number of residents living within walking distance to these strips. While the longer work commute may be difficult to shift to active modes in suburbia, trips to these strips may be much lower hanging fruit. If planners and designers are interested in increasing active travel in suburbia, the findings from this study suggest that trips to strips are a productive topic and area to focus upon. 


\subsection{BIBLIOGRAPHY}

Agrawal, A., M. Schlossberg, et al. (2008). "How Far, by Which Route, and Why? A spatial Analysis of Pedestrian Preference." Journal of Urban Design 13(1): 81-98.

Cervero, R. and K. Kockelman (1997). "Travel demand and the 3Ds: Density, diversity, and design." Transportation Research Part D-Transport and Environment 2(3): 199-219.

Chin, G. K. W., K. P. Van Niel, et al. (2008). "Accessibility and connectivity in physical activity studies: The impact of missing pedestrian data." Preventive Medicine 46(1): 41-45.

Congress for the New Urbanism (1996). Charter of the New Urbanism. Chicago, Congress for the New Urbanism.

CoStar Realty Information Inc. (2010). CoStar Property Professional Database. Bethesda, MD, CoStar.

Ewing, R. (1997). "Is Los Angeles-Style Sprawl Desirable?" J. of the Am. Planning Association Journal of the American Planning Association 63(1): 107-126.

Ewing, R., T. Schmid, et al. (2003). "Relationship between urban sprawl and physical activity, obesity, and morbidity." American Journal of Health Promotion 18(1): 47-57.

Federal Highway Administration. (2008). "Table HM-72 - Highway Statistics 2008 - Urbanized Areas." Retrieved June 6, 2012, from http:/www.fhwa.dot.gov/policyinformation/statistics/2008/hm72.cfm.

Forsyth, A. (2012). NEAT-GIS Protocol. A. Forsyth. Ithaca, New York, Cornell University: 140141.

Forsyth, A., M. Hearst, et al. (2008). "Design and destinations: Factors influencing walking and total physical activity." Urban Studies 45(9): 1973-1996.

Handy, S. (2005). "Smart Growth and the Transportation-Land Use Connection: What Does the Research Tell Us?" International Regional Science Review 28(2): 146-167.

Handy, S. and K. Clifton (2001). "Local Shopping as a Strategy for Reducing Automobile Travel." Transportation 28(4): 317-346.

Hess, P. M., A. V. Moudon, et al. (1999). "Site Design and Pedestrian Travel." Transportation Research Record 1674: 9-19.

International Council of Shopping Centers (1999). ICSC Shopping Center Definitions. ICSC. New York, New York, International Council of Shopping Centers.

International Council of Shopping Centers (2010). U.S Shopping Center Definitions. ICSC. New York, New York, International Council of Shopping Centers.

Jabareen, Y. (2006). "Sustainable Urban Forms." Journal of Planning Education and Research 26(1): 38-52.

Larco, N. (2010). "Suburbia Shifted: Overlooked Trends and Opportunities in Suburban Multifamily Housing." Journal of Architectural and Planning Research 27(1): 69-87.

Larco, N., B. Steiner, et al. (2011). "Pedestrian-Friendly Environments and Active Travel for Residents of Multifamily Housing: The Role of Preferences and Perceptions." Environment and Behavior.

Lee, C. and A. V. Moudon (2006). "The 3Ds+R: Quantifying land use and urban form correlates of walking." Transportation Research Part D-Transport and Environment 11(3): 204-215.

Porta, S. and J. L. Renne (2005). "Linking urban design to sustainability: formal indicators of social urban sustainability field research in Perth, Western Australia." Urban Design International 10(1): 51-64. 
U.S. Energy Information Administration. (2012). "Weekly U.S. All Grades Conventional Retail Gasoline Prices." Retrieved June 26, 2012, from

http://www.eia.gov/dnav/pet/hist/LeafHandler.ashx?n=pet\&s=emm_epm0u_pte_nus_dpg $\& \mathrm{f}=\mathrm{W}$.

US Green Building Council (2008). LEED for Neighborhood Development- FIRST DRAFT. Washington, D.C., US Green Building Council.

Western Australia Planning Commission (2000). Liveable Neighborhoods. Perth, Australia, Western Australia Planning Commission. 



\section{GOTREC \\ AND EDUCATION CONSORTIUM}

P.O. Box 751

Portland, OR 97207

OTREC is dedicated to stimulating and conducting collaborative multi-disciplinary research on multi-modal surface transportation issues, educating a diverse array of current practitioners and future leaders in the transportation field, and encouraging implementation of relevant research results. 